\title{
The Impact of Dry Midlevel Air on Hurricane Intensity in Idealized Simulations with No Mean Flow
}

\author{
ScotT A. BRAun AND JASON A. SiPPEL \\ Laboratory for Atmospheres, NASA Goddard Space Flight Center, Greenbelt, Maryland \\ DAVID S. NOLAN \\ Rosenstiel School of Marine and Atmospheric Science, University of Miami, Miami, Florida
}

(Manuscript received 24 November 2010, in final form 22 June 2011)

\begin{abstract}
This study examines the potential negative influences of dry midlevel air on the development of tropical cyclones (specifically, its role in enhancing cold downdraft activity and suppressing storm development). The Weather Research and Forecasting model is used to construct two sets of idealized simulations of hurricane development in environments with different configurations of dry air. The first set of simulations begins with dry air located north of the vortex center by distances ranging from 0 to $270 \mathrm{~km}$, whereas the second set of simulations begins with dry air completely surrounding the vortex, but with moist envelopes in the vortex core ranging in size from 0 to $150 \mathrm{~km}$ in radius.

No impact of the dry air is seen for dry layers located more than $270 \mathrm{~km}$ north of the initial vortex center ( $\sim 3$ times the initial radius of maximum wind). When the dry air is initially closer to the vortex center, it suppresses convective development where it entrains into the storm circulation, leading to increasingly asymmetric convection and slower storm development. The presence of dry air throughout the domain, including the vortex center, substantially slows storm development. However, the presence of a moist envelope around the vortex center eliminates the deleterious impact on storm intensity. Instead, storm size is significantly reduced. The simulations suggest that dry air slows intensification only when it is located very close to the vortex core at early times. When it does slow storm development, it does so primarily by inducing outward-moving convective asymmetries that temporarily shift latent heating radially outward away from the high-vorticity inner core.
\end{abstract}

\section{Introduction}

High relative humidity $(\mathrm{RH})$ in the middle troposphere has long been recognized as an important factor in determining where tropical cyclones form (Gray 1975, 1979, 1998; McBride 1981). Its favorable role was viewed more in terms of being a necessary climatological condition rather than being a determining factor in whether or not individual cloud clusters went on to develop into tropical cyclones (McBride 1981; McBride and Zehr 1981). However, DeMaria et al. (2001) showed that their formulation of a genesis parameter, of which midlevel moisture is a part, can provide some useful information as to the probability of tropical storm formation. Kaplan

Corresponding author address: Dr. Scott A. Braun, NASA GSFC, Mail Code 612, Greenbelt, MD 20771.

E-mail: scott.a.braun@nasa.gov and DeMaria (2003) showed that high values of 850 700-hPa relative humidity generally favor rapid intensification of tropical cyclones.

Kimball (2006) examined the impact of dry intrusions by perturbing initial moisture in simulations of Hurricane Danny (1997). Kimball varied both the magnitude of the inner-core moisture anomaly $\left(4 \mathrm{~g} \mathrm{~kg}^{-1}\right.$ variations in peak magnitude, maximum in the boundary layer and decreasing with height) and its size (from 250 to $600 \mathrm{~km}$ ). As might be expected, an initial vortex with higher moisture content (for fixed size) generally led to more intense storms, while more extensive moisture anomalies typically led to increased areal extent of rainbands and a larger area of storm-strength winds $\left(17 \mathrm{~m} \mathrm{~s}^{-1}\right)$. Kimball claimed that dry air intrusions into systems with smaller moist envelopes contributed to weakening of those cases, although the differences in minimum central sea level pressure were generally less than $5 \mathrm{hPa}$

DOI: 10.1175/JAS-D-10-05007.1 
prior to landfall for the experiments with peak moisture of $19 \mathrm{~g} \mathrm{~kg}^{-1}$ (her A19 simulations). Because moisture perturbations extended into the boundary layer, the role of midlevel moisture anomalies alone is somewhat ambiguous in these simulations.

Hill and Lackmann (2009) performed idealized simulations to examine the impact of environmental moisture on storm size. Using a fixed initial vortex and inner-core thermodynamic conditions $(80 \% \mathrm{RH}$ within a $100-\mathrm{km}$ radius), they varied the environmental relative humidity between $20 \%$ and $80 \%$. In results that were comparable to Kimball (2006), they found that higher environmental humidities led to increased outer rainband production, larger storms, and broader storm-force wind distributions. In terms of storm intensity, differences among the $20 \%, 40 \%$, and $60 \%$ relative humidity cases were minimal while the $80 \%$ humidity case had a lower minimum central pressure but nearly identical maximum winds. Their results suggest that the environmental humidity has a critical impact on storm size, but a much smaller impact on storm peak intensity (as measured by conventional parameters such as minimum pressure or maximum wind speed).

Dry midlevel air is also one of the potential inhibiting influences of the Saharan air layer (SAL) on the development of tropical cyclones (Dunion and Velden 2004; Wu et al. 2006; Jones et al. 2007; Wu 2007; Dunion and Marron 2008; Sun et al. 2008, 2009; Shu and Wu 2009). Dunion and Velden (2004) suggested that dry SAL air can negatively impact tropical cyclones by fostering enhanced cold downdrafts (Emanuel 1989; Powell 1990) and lowering the convective available potential energy (CAPE) within tropical cyclones. Shu and Wu (2009) suggested that storms often weaken when dry air encroaches to within $360 \mathrm{~km}$ of the storm center. However, in a composite of National Centers for Environmental Prediction (NCEP) Global Data Assimilation System (GDAS) final (FNL) analyses for 41 storms, Braun (2010) found statistically insignificant differences in relative humidity between subsets of storms that strengthened and that weakened in the days after formation, suggesting that dry SAL air only weakly impacts intensity once disturbances reach tropical storm strength. In a statistical analysis of a 30-member ensemble of simulations of Tropical Storm Debby (2006), Sippel et al. (2011) found sensitivity of storm intensification to dry SAL air only up to the early depression stage of the storm, consistent with the results of Braun (2010).

Many studies have focused on dry air as a key mechanism for hurricane suppression or weakening, as a result either of the SAL (Dunion and Velden 2004; Wu et al. 2006; Jones et al. 2007; Wu 2007; Shu and Wu 2009; Sun et al. 2008,2009) or of other dry air sources (Kimball
2006). To investigate this process more carefully, this study uses a set of idealized simulations to examine the impact of a dry midlevel air layer. These simulations also use an environment with no mean flow. More complex simulations with mean flow, including vertical wind shear, are reserved for a future study. Section 2 describes the model setup and experiments, section 3 describes impacts on storm intensity, section 4 describes impacts on storm structure, and section 5 explains how the variations in structure relate to the differing intensification rates of the storms. Conclusions are given in section 6 .

\section{Model setup and experiments}

This study employs the Advanced Research version of the Weather Research and Forecasting (WRF) modeling system (version 3.1; Skamarock et al. 2005) to conduct idealized simulations of the interaction of developing tropical cyclones with dry midlevel air. The model has been applied successfully to the simulation of real tropical cyclones (Davis et al. 2008a,b; Nolan et al. 2009; Vizy and Cook 2009; Braun et al. 2010; Wang et al. 2010, among many others) and for idealized simulations (Nolan 2007; Nolan et al. 2007b; Nolan and Rappin 2008; Hill and Lackmann 2009). In particular, Davis et al. (2008b) showed that the WRF model performance in real-time simulations was competitive with, and in some cases superior to, other operational models. Here, three grids nesting down to $2-\mathrm{km}$ horizontal grid spacing are employed in order to reasonably represent the convection. The outer grid has a horizontal grid spacing of $18 \mathrm{~km}$ and contains $240 \times 240$ grid points in the $x$ and $y$ directions. Two nested meshes are used with the following grid spacings and grid dimensions: $6 \mathrm{~km}$ and $120 \times 120$, and $2 \mathrm{~km}$ and $240 \times 240$. All grids use 49 vertical levels with a model top at $20 \mathrm{~km}$. Physics options include the Yonsei University boundary layer scheme (Noh et al. 2003; Hong et al. 2006), the fifth-generation Pennsylvania State University-National Center for Atmospheric Research (NCAR) Mesoscale Model (MM5) similarity theory surface-layer scheme (Zhang and Anthes 1982; Skamarock et al.2005), the Kain-Fritsch cumulus scheme (Kain and Fritsch 1990, 1993; Skamarock et al. 2005) on the 18-km grid, and the WRF single-moment three-class simple ice cloud microphysics scheme (Hong et al. 2004) on all grids. Radiative processes are not included.

Initial and boundary conditions are derived loosely following Nolan et al. (2007a) and Nolan and Rappin (2008). The boundary conditions are doubly periodic. The domain is on an $f$ plane with background Coriolis parameter of $f=5.0 \times 10^{-5} \mathrm{~s}^{-1}$. The initial vortex is specified as a modified Rankine vortex with solid body rotation out to a radius of maximum winds (RMW) of 
TABLE 1. Simulation names and descriptions.

\begin{tabular}{|c|c|}
\hline $\begin{array}{l}\text { Simulation } \\
\text { name }\end{array}$ & Description \\
\hline CNTL & $\begin{array}{l}\text { Control run with uniform non-SAL } \\
\text { environment }\end{array}$ \\
\hline DRY270 & $\begin{array}{l}\text { Dry air located northward of } 270 \mathrm{~km} \text { north of } \\
\text { vortex center }\end{array}$ \\
\hline DRY144 & $\begin{array}{l}\text { Dry air located northward of } 144 \mathrm{~km} \text { north of } \\
\text { vortex center }\end{array}$ \\
\hline DRY90 & $\begin{array}{l}\text { Dry air located northward of } 90 \mathrm{~km} \text { north of } \\
\text { vortex center }\end{array}$ \\
\hline DRY0 & Dry air located northward of vortex center \\
\hline DRYALL0 & Dry air throughout domain, including vortex \\
\hline DRYALL75 & $\begin{array}{l}\text { Dry air throughout domain except within } \\
75-\mathrm{km} \text { radius }\end{array}$ \\
\hline DRYALL150 & $\begin{array}{l}\text { Dry air throughout domain except within } \\
150-\mathrm{km} \text { radius }\end{array}$ \\
\hline
\end{tabular}

$100 \mathrm{~km}$ and a wind decay of $1 / r^{a}$ beyond the RMW, with $a=0.5$. The maximum wind speed is $15 \mathrm{~m} \mathrm{~s}^{-1}$ at $4.5-\mathrm{km}$ altitude. The sea surface temperature is set to $28^{\circ} \mathrm{C}$ (301.15 K). The background environment representing non-SAL tropical air is specified by the Dunion and Marron (2008) non-SAL sounding. For the control run (CNTL) that excludes a dry midlevel air layer, this environment is specified for the entire domain. In these simulations, there is no mean environmental flow, which simplifies the problem to the issue of whether the interaction between the dry air and the storm circulation is sufficient to affect storm evolution.

Several different configurations for the dry air layer are utilized. The first, labeled DRY270, places a dry air layer at all grid points farther north than $270 \mathrm{~km}$ (15 grid points on the outer domain) north of the initial storm center. North of this boundary, the relative humidity in the $850-600-\mathrm{hPa}$ layer is set to $25 \%$. Note that composite relative humidity fields for weakening storms in Fig. 13 of Braun (2010) show the dry air typically farther than $400 \mathrm{~km}$ from the storm center, so the position of the dry air boundary is closer to the vortex than is suggested by NCEP final analyses. Additional simulations, labeled DRY144, DRY90, and DRY0 move the dry air boundary successively closer to the vortex center until in the last case the dry air boundary is at the center. The final set of simulations involves the placement of the dry air layer over the entire domain. In DRYALL0, the dry air extends throughout the vortex and its surroundings. Given that storms typically form within an envelope of moist air, in DRYALL150 and DRYALL75 a moist envelope (using the non-SAL sounding) is prescribed from the center of the vortex to a radius of 150 and $75 \mathrm{~km}$, respectively, but with dry air otherwise surrounding the vortex. A summary of all experiments is given in Table 1. In the discussion that follows, the minimum sea level pressure and maximum instantaneous wind speed are taken as measures of storm intensity.

The storm center was determined, as in Braun (2002), at every model output time using the surface pressure field. Rather than using the location of the minimum pressure, we used the horizontal distribution of pressure to determine an approximate geometric centroid. The location of the minimum pressure was used as a first guess for the center, and a variational approach then adjusted the center location to minimize the azimuthal variance of the pressure field at all radii within $150 \mathrm{~km}$.

\section{Impacts on storm intensity}

The results from Fig. 1 suggest that the dry midlevel air can act as a brake on development, but only if it is able to penetrate to very small radius during the early stages of development. First, the CNTL run with no dry layer starts with an initial minimum central pressure of $1012 \mathrm{hPa}$ and takes about 2 days to reach $1000 \mathrm{hPa}$ and begin a more rapid intensification process. By day 7 , the central pressure drops to a minimum of $940 \mathrm{hPa}$ and the maximum wind speed reaches $\sim 50 \mathrm{~m} \mathrm{~s}^{-1}$, remaining approximately steady thereafter. Meanwhile, the minimum pressure and maximum wind speed in DRY270 are almost identical to those in the CNTL run, suggesting little impact of the dry air on storm intensity for initial separation distances greater than $270 \mathrm{~km}$. As the separation distance is reduced from $270 \mathrm{~km}$ to 144 (DRY144), 90 (DRY90), and $0 \mathrm{~km}$ (DRY0), the dry air increasingly slows or delays the intensification of the vortex, although all cases reach approximately the same maximum intensity by the end of the simulations. ${ }^{1}$

To illustrate why the dry air has little impact on storm intensity for the DRY270 case despite its proximity to the vortex, Fig. 2 shows the azimuthally averaged relative humidity and radial winds for the DRY270 simulation at 5 days. Dry air with relative humidity less than $50 \%$ does not penetrate (in the average) inside of $300 \mathrm{~km}$ from the vortex center. The primary reason is that the radial flow in the $850-600-\mathrm{hPa}$ layer is characterized by weak inflow $\left(<2 \mathrm{~m} \mathrm{~s}^{-1}\right)$ outside $\sim 225 \mathrm{~km}$ and weak outflow at smaller radius. This is similar to several previous simulation studies (Liu et al. 1997; Braun 2006; Smith et al. 2009) where the bulk of the radial inflow is in the surface boundary layer, typically below $\sim 900 \mathrm{hPa}$ or

\footnotetext{
${ }^{1}$ The simulations achieve the same final intensity because, given enough time, the dry air is eventually moistened so that all systems reach their maximum potential intensity (within the context of the modeling system and the choices for parameterizations). The maximum potential intensity here is determined by the imposed SST and mean sounding.
} 
a)
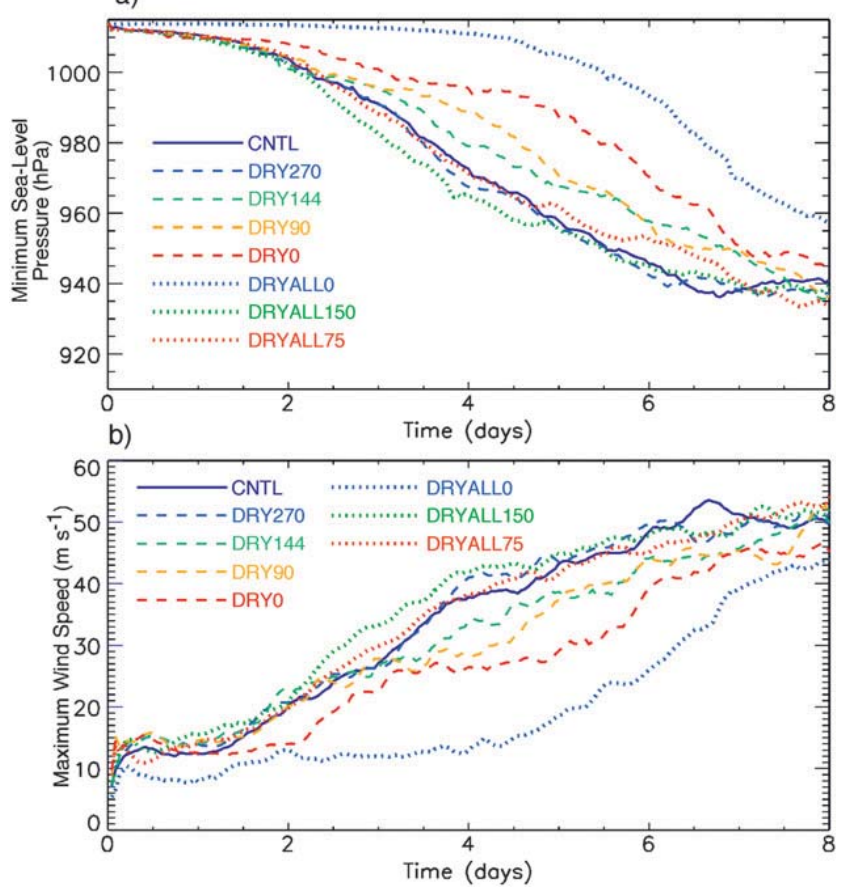

FIG. 1. Time series of (a) minimum sea level pressure and (b) maximum wind speed for all simulations. The solid line is the CNTL run, the dashed lines are the runs with dry air north of a specified latitude, and the dotted lines are for runs with dry air throughout the domain except for a moist envelope within the vortex.

$1-\mathrm{km}$ altitude. This figure shows that, in the absence of mean environmental flow, there is no mechanism for the dry air to penetrate into the inner core of convection and that the only way for it to affect storm development is to begin in the inner-core region at initial times.

Figure 3 illustrates the situation where dry air exists in the initial inner core. In this figure, relative humidity at $3-\mathrm{km}$ altitude from the $18-\mathrm{km}$ grid of DRY0 is shown for selected times. The southern half of the vortex is initially collocated with an area of enhanced humidity (Fig. 3a) resulting from the cool anomaly below the balanced midlevel vortex, and the boundary of the dry midlevel air goes through the center of the vortex. The cyclonic winds associated with the vortex extend well into the dry air and, after 2 days (Fig. 3b), they have wrapped this dry air nearly all the way around the vortex. In addition to the southward displacement of dry air, the moister air initially on the southern side of the vortex gets displaced northward into the dry air mass. Over time (Figs. 3c,d), the dry air gets increasingly wrapped around the vortex and axisymmetrized, lowering the overall relative humidity in the environment of the vortex compared to CNTL. The effect on storm intensity (Fig. 1) is to delay or slow intensification of the storm by up to 2 days, although the storm reaches a maximum intensity similar to that of CNTL by the end of the simulation period (i.e., 8 days).
As might be expected, the largest impact of dry air is found when the dry layer extends across the entire domain (case DRYALL0). In this case, deep convection does not begin until the end of the third day, after shallow convection has gradually moistened the midlevels, with intensification of the vortex then ensuing (Fig. 1). The storm begins a period of more rapid intensification on the fifth day, approaching the maximum intensity of the other simulations after 8 days.

Both DRYALL0 and DRY0 are generally unrealistic for development of actual tropical disturbances since these disturbances virtually always form within some moist envelope of air associated with easterly waves (Dunkerton et al. 2009; Hopsch et al. 2010). This fact suggests that a more realistic initial condition for an environment with dry air surrounding the vortex would include a moist envelope with at least moderate $(>60 \%)$ relative humidity within some radius from the initial storm center. To examine the impact of a moist envelope collocated with the vortex, two experiments were performed in which the dry midlevel air (from case DRYALL0) within some radius $R$ was replaced by the non-SAL sounding. Given that the initial radius of maximum wind is $100 \mathrm{~km}$, we tested $R=150 \mathrm{~km}$ and $R=75 \mathrm{~km}$. Results from the latter case will be emphasized since both simulations produce similar results (Fig. 1).

Initially, moist $(>80 \% \mathrm{RH})$ conditions exist only within the small predefined region near the storm center and the circulation is otherwise surrounded by very dry air. Over time, the moist region expands as convection increases winds within the boundary layer, driving larger fluxes of sensible and latent heat. The intensity of the storm in DRYALL75 as a function of time (Fig. 1) is essentially identical to that in the CNTL case, suggesting that a vortex with even a modest-sized moist envelope will not necessarily be adversely affected by dry midlevel air, even when completely surrounded by it. This result is qualitatively consistent with those of Hill and Lackmann (2009), who found that relative humidity outside a $100-\mathrm{km}$ radius had very limited impact on storm central pressure and maximum wind speed.

\section{Impacts on storm structure}

The intrusion of dry midlevel air can produce marked changes in storm structure. To illustrate the characteristics of these changes, Figs. 4 and 5 show horizontal distributions of simulated midlevel $(3 \mathrm{~km})$ relative humidity and near-surface radar reflectivity, respectively, for $12 \mathrm{~h}$ and 3 days into the simulations from CNTL, DRY0, and DRYALL75. At $12 \mathrm{~h}$ into the simulation, the CNTL run shows two nearly concentric rings of high 


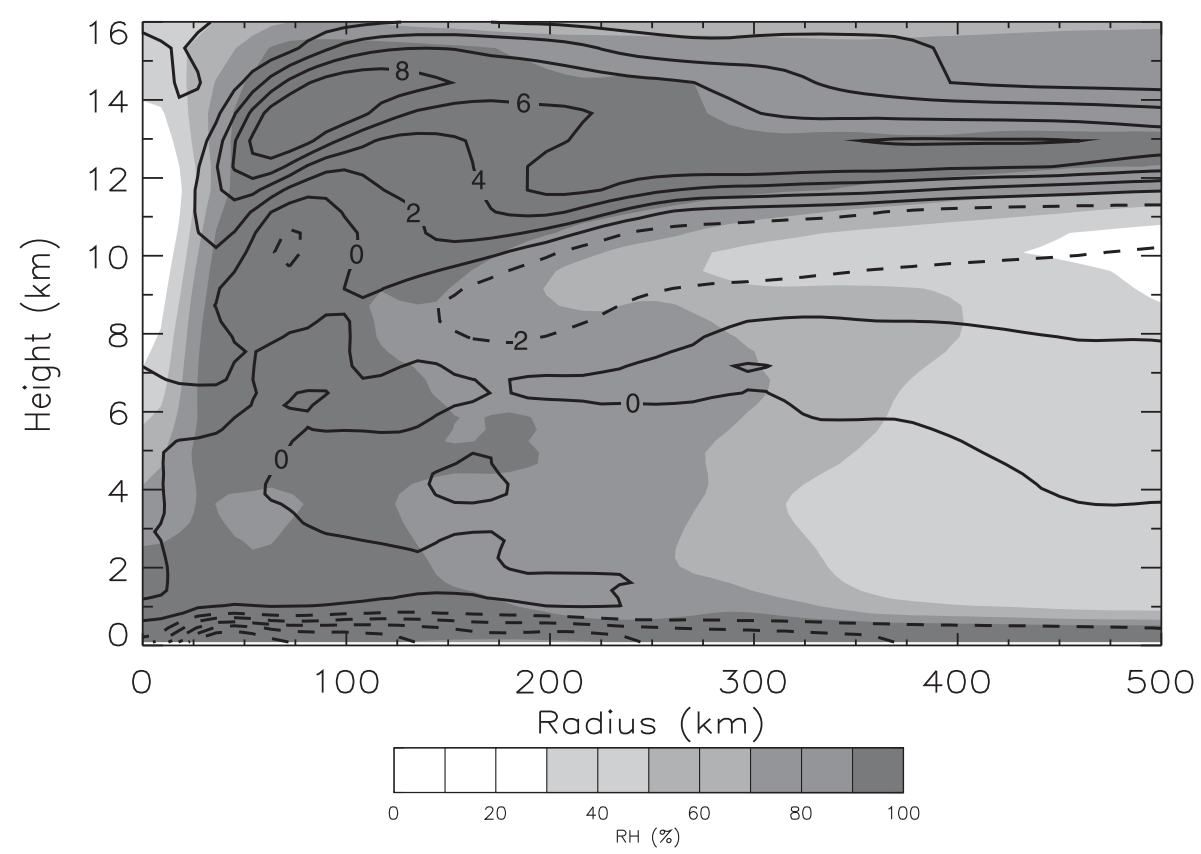

FIG. 2. Azimuthally averaged RH (shading; contours at 30\%, $50 \%, 70 \%$, and $90 \%$ ) and radial velocity (contours, $2 \mathrm{~m} \mathrm{~s}^{-1}$ intervals, negative values dashed) from the 18 -km grid of simulation DRY270 at 5 days.

relative humidity and reflectivity (Figs. $4 a$ and 5a). An inner ring lies just inside the initial radius of maximum wind and an outer ring is along the edge of a circular cold pool region formed by the initial convection (to be discussed in section 5). These rings should not be confused with convective organization that would be associated with secondary eyewall formation; rather, they are a consequence of the strong symmetry of the initial conditions. In contrast, in the DRY0 simulation, dry air has wrapped into the eastern portion of its vortex (Fig. 4c), largely suppressing any convection there (Fig. 5c). As a result, the precipitation is highly asymmetric in the outer convective ring and very limited in the inner ring. The horizontal precipitation structure of the storm in the DRYALL75 simulation (Fig. 5e) shows suppressed development of the outer convective ring but several convective cells within an inner convective ring.

The suppressing influence of the dry air is illustrated in Fig. 6a, which shows the horizontal distribution of relative humidity and simulated radar reflectivity $6 \mathrm{~h}$ into the DRY0 simulation. The deep convection, as indicated by the higher reflectivities, is contained within the moist portion of the vortex. Dry air is wrapping around the southern side of the vortex. Convection within this dry region is generally limited to a depth of just $3 \mathrm{~km}$ (Fig. 6b, between $\sim 170$ and $300 \mathrm{~km}$ ) except along the western edge of the cold pool (Fig. 6c, near 130-140 km) where it penetrates to just above $4 \mathrm{~km}$. The curvilinear pocket of moderate to high humidity within the broader dry air mass is associated with this $\sim 4$-km-deep convection along the cold-pool edge. Vertical cross sections through this feature (Figs. 6b,c) show that the convection generally does not penetrate above the dry layer, while convection in the moist layer easily reaches $10 \mathrm{~km}$ or higher. The shallow convection in the dry air results from a reduction of boundary layer equivalent potential temperature $\theta_{e}$ caused by cold downdrafts, thereby reducing the parcel $\theta_{e}$ entering cloud base, and the rapid entrainment of dry air as the convective plumes rise.

Generally similar differences between CNTL and DRY0 continue over the next several days of the simulations. By the end of day 3, the CNTL simulation shows a very symmetric system of tropical storm strength (Figs. $4 \mathrm{~b}$ and $5 \mathrm{~b}$ ), with a nascent eyewall as well as inner and outer rainband structures. In the DRY0 simulation, the only remaining very dry air $(<50 \%)$ is found at a radius of about $200 \mathrm{~km}$ (Fig. 4d). Although a weak asymmetry in the relative humidity field exists, with humidities between $70 \%$ and $80 \%$ prevalent on the eastern side of the storm compared to higher humidities elsewhere, the dry air has largely been axisymmetrized. Despite the axisymmetrization of the humidity field and formation of a nascent eyewall (Fig. 5d), the convection remains highly asymmetric, with the major portion of the precipitation in the southwestern quadrant. By 3 days into DRYALL75, a symmetric eyewall has formed (Fig. 5f), but with a radius that is only half that in the CNTL simulation.

The evolution of the precipitation structure in the CNTL，DRY270，DRY144，DRY90，DRY0，and 

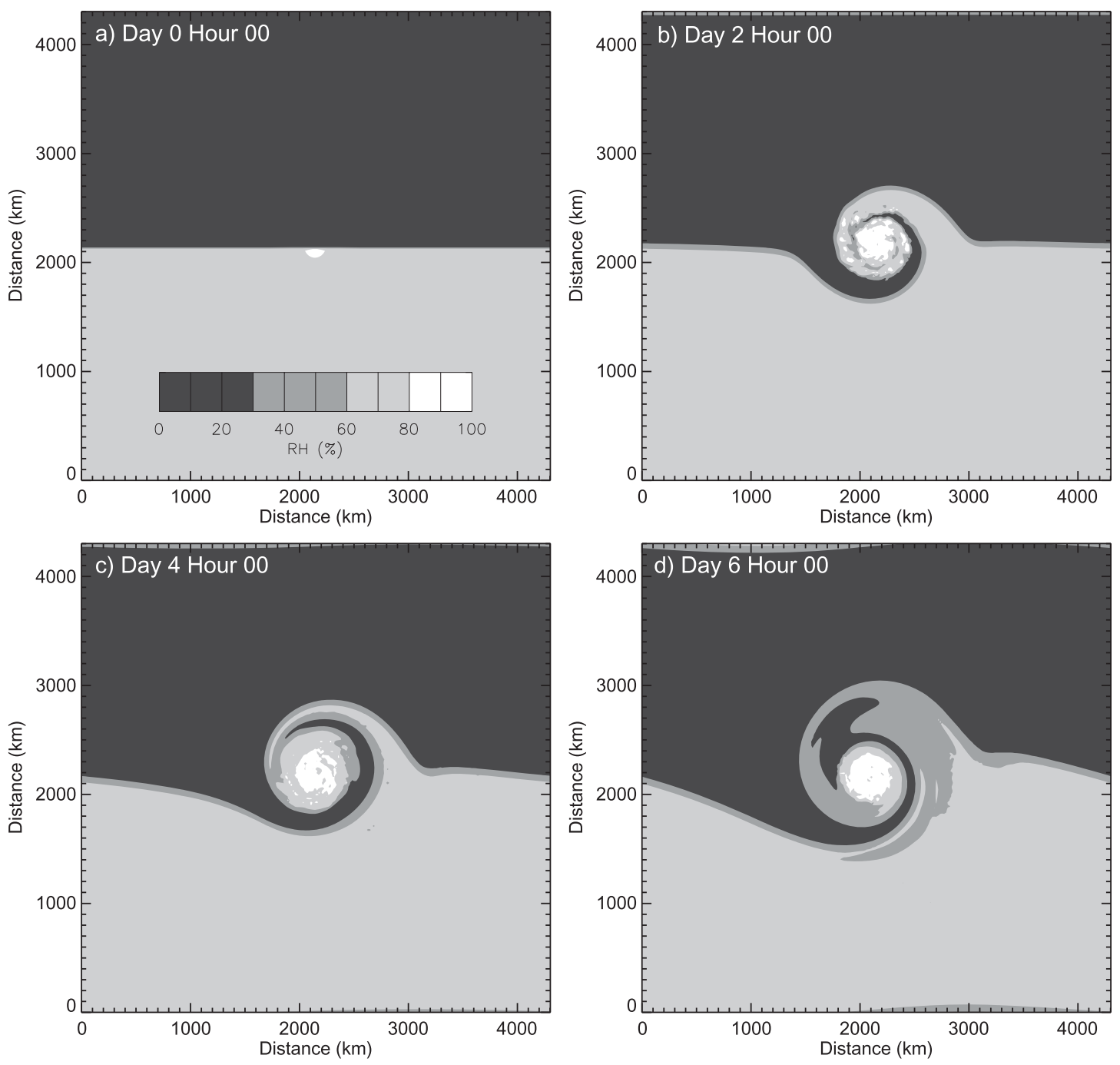

FIG. 3. RH at 3-km altitude from the DRY0 simulation (18-km coarse grid domain) at (a) the initial time, and after (b) 2, (c) 4, and (d) 6 days. The color scale is shown in (a).

DRYALL75 simulations is depicted in Fig. 7 in terms of the radial and azimuthal variations of the $3-\mathrm{km}$-level rain mixing ratio with time for the first 6 days of the simulations. In CNTL (Fig. 7a), convection begins near a radius of $70 \mathrm{~km}$ and propagates outward along an outflow boundary. Two more cycles of convection and outflow occur before the precipitation becomes more continuous in time after $30 \mathrm{~h}$. The precipitation in the nascent eyewall contracts and intensifies with time up to 4.5 days and then moves slowly outward between 5 and 6 days. The precipitation field is very symmetric at early stages (Fig. 7b), but it exhibits a weak wavenumber-1 asymmetry between 3 and 5 days.

When dry air is placed $270 \mathrm{~km}$ north of the vortex center, the evolution of the radial distribution of rain (Fig. 7c) and the storm intensity are very similar to CNTL. A stronger wavenumber-1 asymmetry (Fig. 7d) becomes noticeable as early as $12 \mathrm{~h}$ and better defined after $30 \mathrm{~h}$. Although the rain field is asymmetric, precipitation still generally encloses most of the developing eye, even if only weakly. When the dry air is initially placed at $144 \mathrm{~km}$ from the center, the rain field (Fig. 7e) still steadily contracts, but it intensifies more slowly. A more pronounced change occurs in the azimuthal variation of the rain field (Fig. 7f), which has a much more well-defined wavenumber- 1 asymmetry. The asymmetry is sufficiently strong that a significant portion of the forming eyewall has little or no rain through much of the 6 days shown.

When dry air is initially placed at a radius of $90 \mathrm{~km}$, just inside the initial 100-km radius of maximum winds, an important change in precipitation evolution occurs (Fig. 7g). Unlike the fairly continuous contraction of the precipitation fields in the earlier cases, the precipitation field shows little or no contraction between 1.5 and 3.5 days. After that time, the rain maximum contracts 

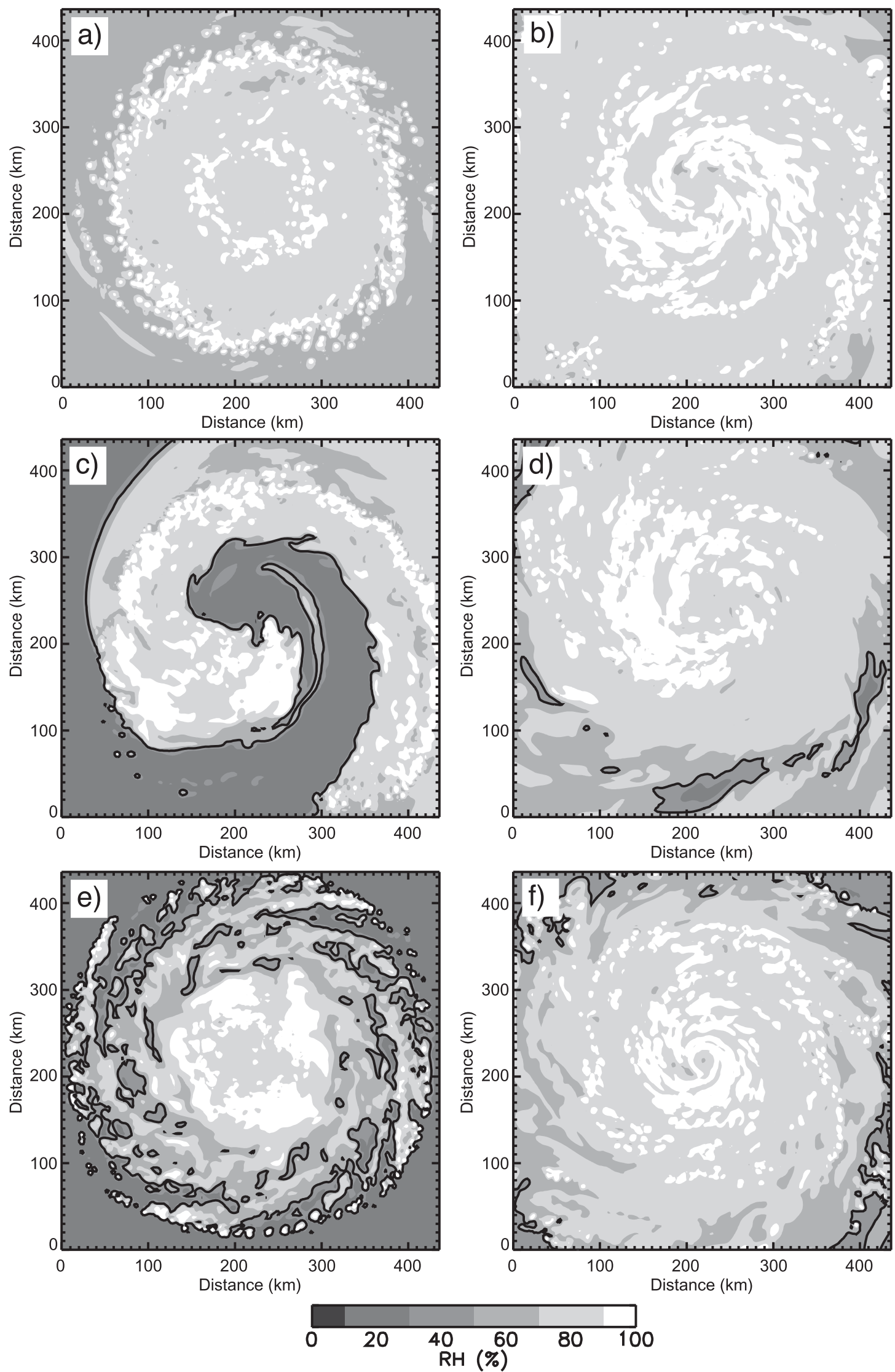

FIG. 4. RH at 3-km altitude from the 2-km resolution domain for (left) $12 \mathrm{~h}$ and (right) 3 days into the simulation, for (top) the CNTL simulation, (middle) the DRY0 simulation, and (bottom) the DRYALL75 simulation. Thick solid contours are drawn at $50 \% \mathrm{RH}$. 

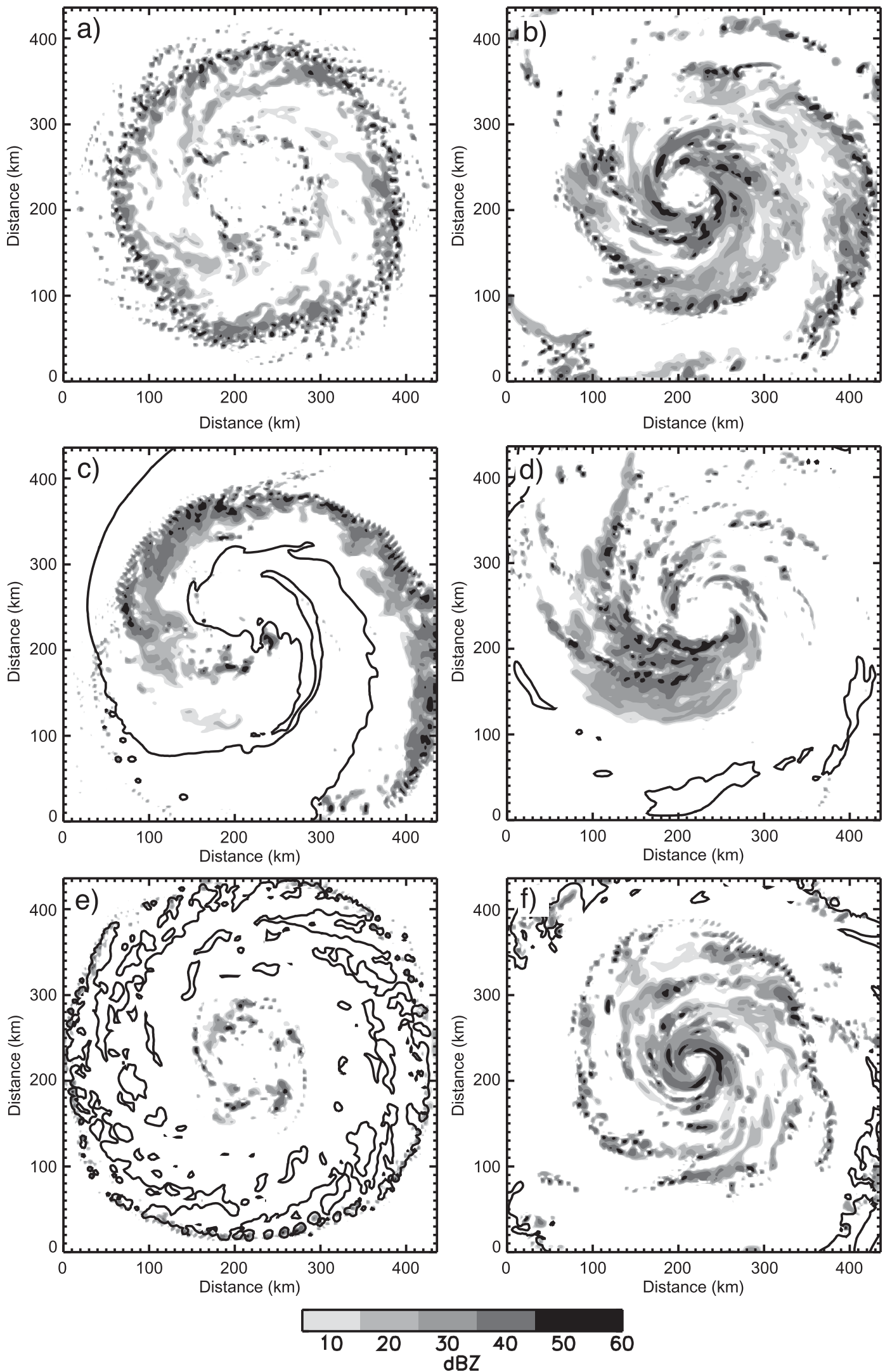

FIG. 5. Simulated radar reflectivity at $0.5-\mathrm{km}$ altitude from the $2-\mathrm{km}$ resolution domain for (left) $12 \mathrm{~h}$ and (right) 3 days into the simulation, for (top) the CNTL simulation, (middle) the DRY0 simulation, and (bottom) the DRYALL75 simulation. Thick solid contours show the 50\% RH contours from Fig. 4. 

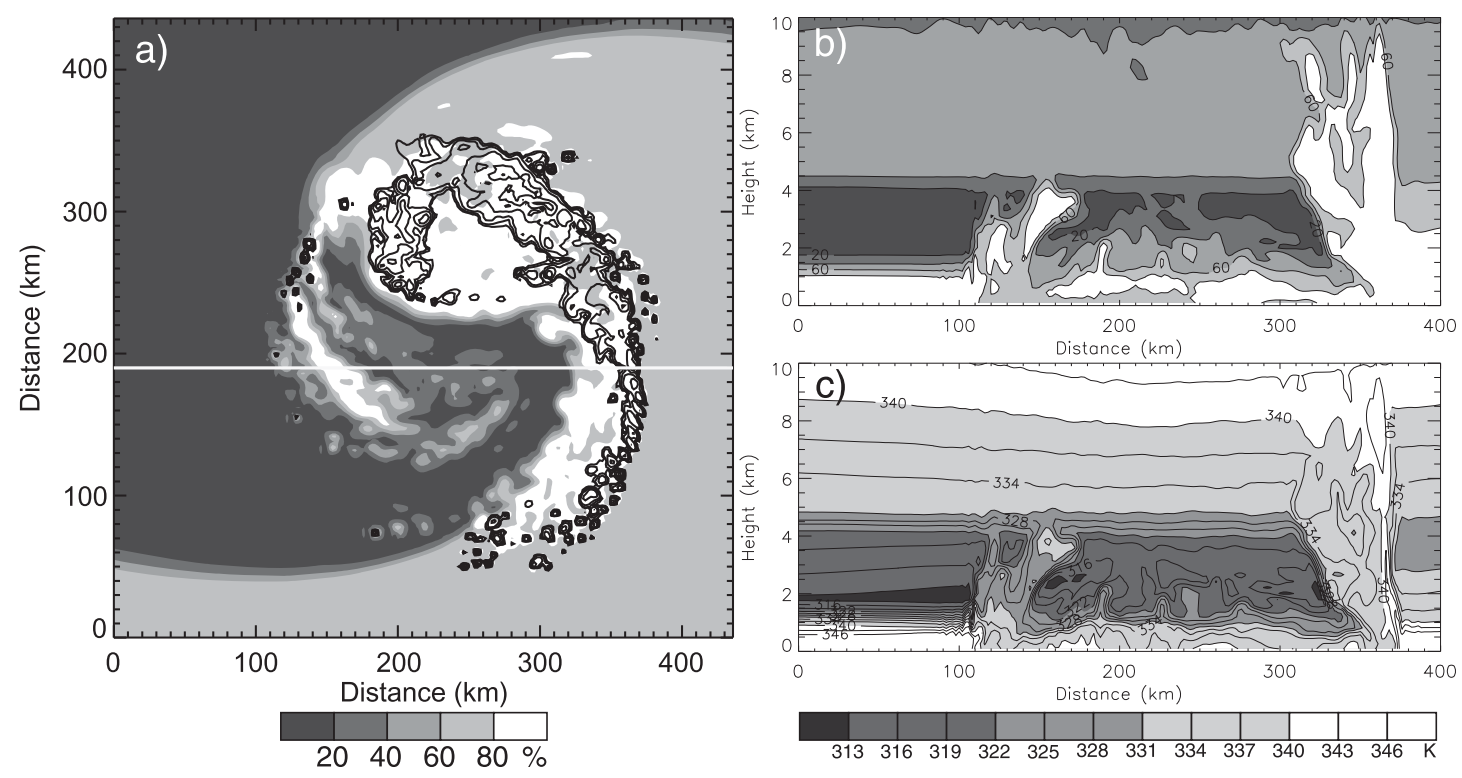

FIG. 6. (a) RH (shading) and simulated radar reflectivity (contours, 10-dBZ interval, starting at $5 \mathrm{~dB} Z$ ) at 3-km altitude from the innermost grid of the DRY0 simulation at $6 \mathrm{~h}$. The white line indicates the location of the vertical cross sections. (b),(c) Vertical cross sections of (b) RH (20\% contour interval) and (c) $\theta_{e}$ (3-K contour interval). The color scale for (a) and (b) is in the lower-left part of the figure. The color scale for (c) is in the lower-right portion of the figure.

from about $60-\mathrm{km}$ radius to about $25-\mathrm{km}$ radius during the next $24 \mathrm{~h}$ and then intensifies after 4.5 days. As in the DRY144 simulation, the structure in DRY90 is characterized by a pronounced wavenumber-1 asymmetry through the first 6 days of the storm's evolution (Fig. 7h), with little or no rain over half the eyewall. A very similar evolution is seen in DRY0 (Figs. 7i,j), with the main difference being a greater reduction in rain during the first 2 days of simulation as the dry air occupies half the area of the initial vortex. Similar to DRY90, precipitation remains weak and steady prior to the time of intensification (near 4.75 days), at which time the radius of rainfall contracts and the rain amount gradually increases. The pronounced wavenumber-1 asymmetry (see Fig. 5d) is also evident in DRY0.

When a small moist envelope is included, but the storm is otherwise surrounded by dry air (DRYALL75; Figs. 7k,1), the evolution is very similar to CNTL except that rain is concentrated near a radius of $20-30 \mathrm{~km}$ rather than $30-40 \mathrm{~km}$ in CNTL. The radial structure is characterized by rapid contraction of the nascent eyewall during the first 2 days and slow expansion after 5 days. Outward-moving rainbands occur frequently through the first 5 days of simulation. The azimuthal structure shows a somewhat more pronounced wavenumber-1 asymmetry compared to CNTL, but this asymmetry is much weaker than that found in the other simulations with dry air.

\section{The relative impacts of cold pools and enhanced storm asymmetry}

The intrusion of dry air into the vortex can have multiple effects including 1) suppression of deep convective development because of boundary layer cooling from downdrafts, 2) suppression of deep convection by entrainment of dry air into rising clouds, and 3) generation of precipitation asymmetries that persist well beyond the time of axisymmetrization of the humidity field. In this section, we examine the roles of these mechanisms in the impact of the dry midlevel air on storm intensity.

Figure 8 shows plots of the near-surface $(90 \mathrm{~m}) \theta_{e}$ and simulated radar reflectivity at $12 \mathrm{~h}$ for the CNTL, DRY90, DRY0, and DRYALL75 simulations. The azimuthally averaged near-surface $\theta_{e}$ distributions as a function of radius and time are shown in Fig. 9 for each of these cases. In CNTL (Fig. 8a), a symmetric cold outflow is generated by the initial convection, but the interior region where surface winds are largest recovers most quickly. A nearly identical pattern is found in the DRY270 simulation (not shown). Figure 9a shows the formation and outward movement of the initial cold pool, as well as several additional outward-moving cold pools that occur over the next 2 days. After about 2.5 days, $\theta_{e}$ rapidly increases in the eye and increases more slowly outside of the eyewall as the storm intensifies.

When dry air is placed $90 \mathrm{~km}$ north of the vortex center (DRY90), it wraps around the western side of the 

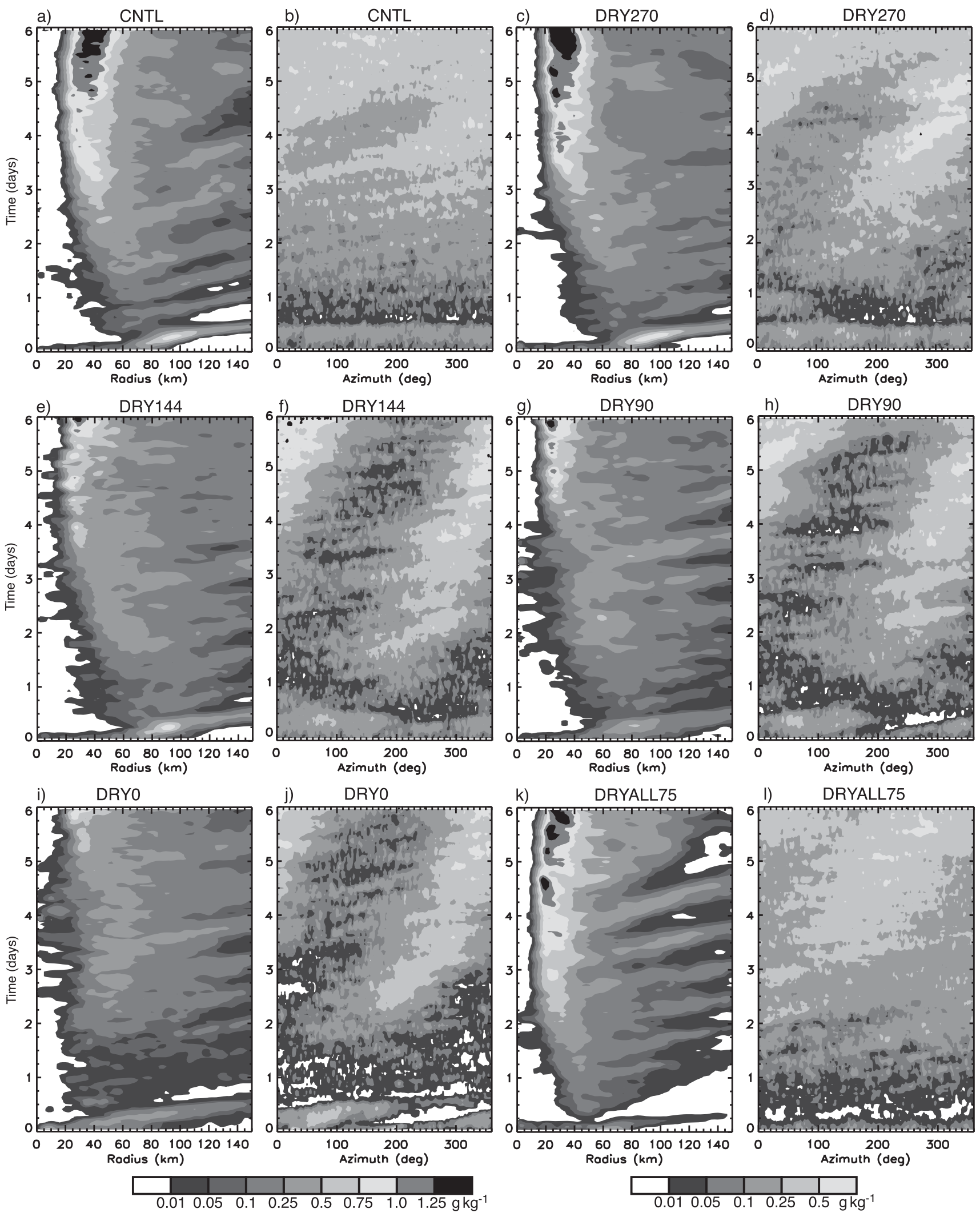

FIG. 7. (column 1),(column 3) Radius vs time distributions of azimuthally averaged 3-km rainwater mixing ratio. The corresponding color scale is the lower-left scale. (column 2),(column 4) Azimuth vs time distributions of the radially averaged (0-150-km radius) rainwater mixing ratio. The corresponding color scale is the lower-right scale. The corresponding simulation name is given above each panel. 

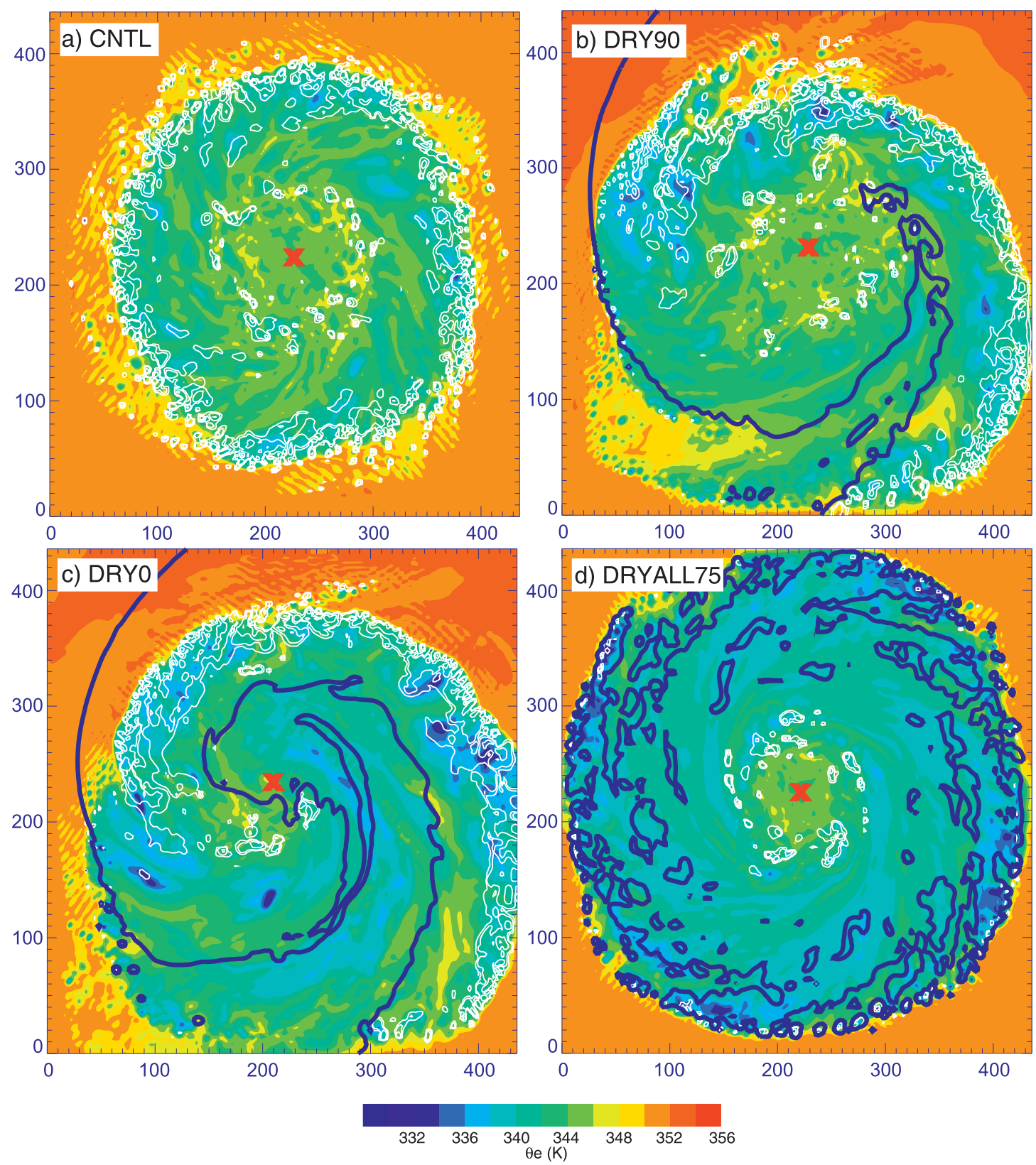

FIG. 8. Equivalent potential temperature $\theta_{e}$ at the lowest model level $(90 \mathrm{~m})$ at $12 \mathrm{~h}$ into the simulations from the 2-km grid for (a) the CNTL run, (b) the DRY90 run, (c) the DRY0 run, and (d) the DRYALL75 run. Thick blue contours show the $50 \% \mathrm{RH}$ contours at $3-\mathrm{km}$ altitude. Thin white contours show simulated radar reflectivity at 2-km altitude every $10 \mathrm{dBZ}$ starting at $25 \mathrm{~dB} Z$. The thick red $\times$ marks the center location.

vortex and enters the precipitation area near its southern end by $6 \mathrm{~h}$ (not shown) and extends into the eastern portion of the storm by $12 \mathrm{~h}$ (Fig. $8 \mathrm{~b}$ ). [In DRY144, the pattern is similar to DRY90, but the dry tongue has only just entered the storm at its southern edge by $12 \mathrm{~h}$ (not shown)]. The presence of dry air within the storm's circulation produces two effects. First, it enhances the cold downdrafts in the southernmost portion of the precipitation immediately ahead of the dry tongue, which then expands to the south and east of the center. Second, it completely inhibits precipitating convection in the tongue of dry air. Differences in the radial distribution of azimuthally averaged near-surface $\theta_{e}$ between DRY90 (Fig. 9b) and CNTL are small and vary between positive and negative values through the first 3 days of simulation. The main exception is at radii greater than $90 \mathrm{~km}$ (i.e., the initial radial distance of the dry air) during the first 1.5 days of simulation, where DRY90 is generally about $1-2 \mathrm{~K}$ cooler.

Very dramatic changes in near-surface $\theta_{e}$ occur in DRY0 (Fig. 8c) compared to CNTL and DRY90. Colder 

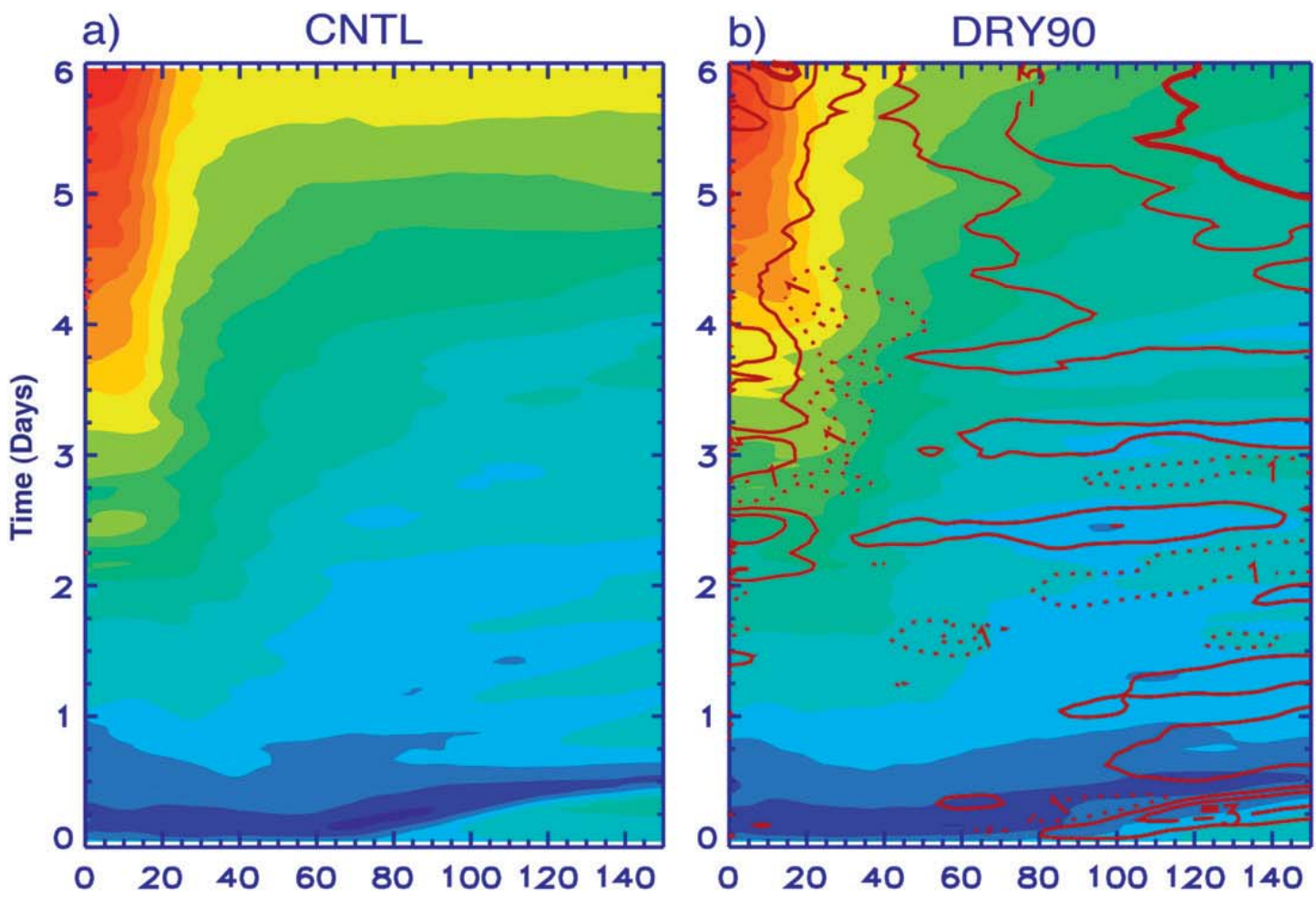

c)

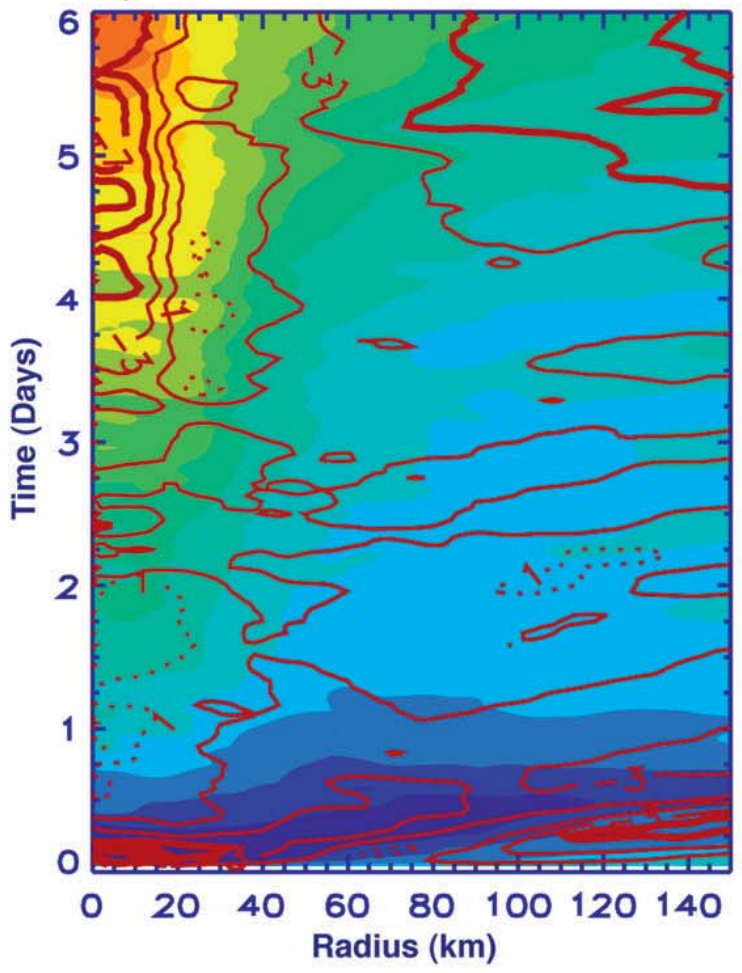

d)

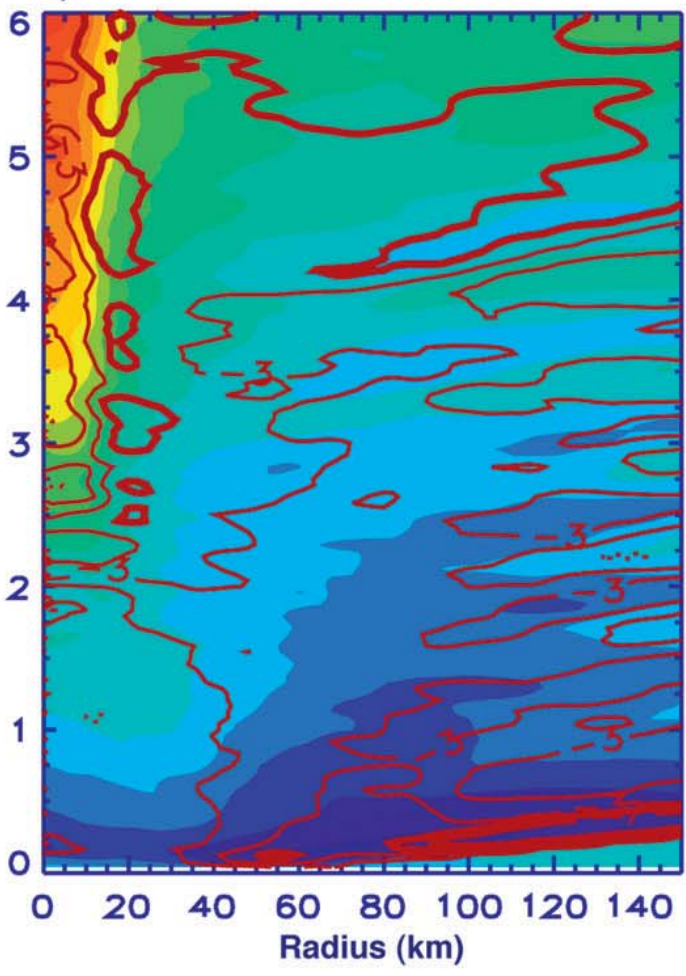

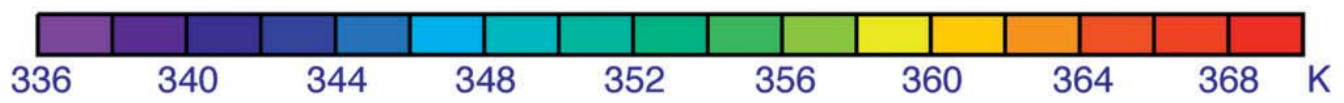

FIG. 9. Radius vs time distributions of the azimuthally averaged $\theta_{e}$ (shading) at the lowest model level (90 m) for (a) CNTL, (b) DRY90, (c) DRY0, and (d) DRYALL75. Contours show the difference from the CNTL run (e.g., CNTL - DRY0), with negative values indicated by solid lines and positive values by dotted lines. The contour interval is $2 \mathrm{~K}$, starting at $-7 \mathrm{~K}$, with differences $\leq-5 \mathrm{~K}$ shown as thick contours. 
downdrafts lead to more expansive cold pools than in CNTL, particularly to the south and east during the first $12 \mathrm{~h}$. The surface pressure center is initially displaced toward the moist air during the first $12 \mathrm{~h}$, but it then realigns with the circulation center and the core of higher $\theta_{e}$ air by $24 \mathrm{~h}$ (not shown). Figure $9 \mathrm{c}$ shows that the azimuthal mean $\theta_{e}$ pattern is much colder for DRY0 than CNTL during the first 1.5 days, similar to CNTL between 1.5 and 2.5 days, and then lower than CNTL at later times. This latter result is partly because of $\theta_{e}$ increases in CNTL associated with its intensification, but it also results from cold downdrafts that are generated within DRY0 (discussed below). The $\sim 36$-h length of time during which DRY0 has colder $\theta_{e}$ values at the beginning of the simulation is comparable to the roughly 2-day delay in intensification of the storm relative to CNTL. It is also evident from Figs. $5 \mathrm{c}$ and $8 \mathrm{c}$ that precipitating convection is virtually always absent from the dry tongue during its initial intrusion into the precipitation regions. This result suggests strong suppression of deep convection by the dry air through the combined effects of boundary layer cooling and entrainment of dry air into the rising cumulus towers.

One might conclude from the above findings that the enhancement of cold downdrafts resulting from the dry intrusion is the primary cause for the delay in storm intensification in DRY144, DRY90, and DRY0, but the explanation appears to be more complex. For example, although DRY90 is weaker than CTRL, the differences in near-surface $\theta_{e}$ between CNTL and DRY90 are small (Figs. 9a,b) prior to day 4 when much of the delay in the intensification of DRY 90 occurs. In addition, the relatively strong storm in DRYALL75 presents compelling evidence that cold downdrafts alone may not be the main mechanism for delay. This case produces the coldest downdrafts of the four simulations, with large areas at $12 \mathrm{~h}$ (Fig. 8d) with $\theta_{e}>8 \mathrm{~K}$ cooler than in CNTL. The cold air spreads out symmetrically surrounding an inner region of moderate $\theta_{e}$ values $(\sim 344-345 \mathrm{~K})$ that is similar to that found in the inner regions of all of the simulations. This simulation is colder than CNTL (Fig. 9d) at most radii outside the eyewall throughout the simulation and is up to $3 \mathrm{~K}$ cooler than DRY0 at radii greater than $40 \mathrm{~km}$ at most times through the first 3 days of simulation. Despite the colder boundary layer air, DRYALL75 has an intensity that is nearly identical to CNTL throughout the simulation.

Considering the inability of downdrafts to impede intensification in DRYALL75, combined with the strong wavenumber-1 asymmetries in convection that are prominent in DRY144, DRY90, and DRY0, we suggest that the delayed intensification in these latter cases is strongly tied to their asymmetric structure. The asymmetric structure is a result both of the direct suppression of convection in the areas of intruding dry air (from lowering of boundary layer $\theta_{e}$ and entrainment) and of asymmetries possibly forced by asymmetric patterns of cold outflow that extend beyond the intruding dry air tongue. The remainder of this section will address this issue.

To focus the discussion, Fig. 10 shows the time series of maximum azimuthally averaged tangential wind at the lowest model level $(90 \mathrm{~m})$ for the DRY270, DRY144, DRY90, and DRY0 simulations. The intensity in the DRY270 simulation is similar to CNTL (see Fig. 1), with steady intensification from about 1 to 3 days, a period of more rapid intensification through day 4 , and then moderate intensification through day 6. The DRY144 simulation begins similarly. By 2.3 days, it is about $2 \mathrm{~m} \mathrm{~s}^{-1}$ stronger than DRY270 but then undergoes a period of slow growth between 2.3 and 3 days. Between 3 and 4 days, DRY144 undergoes moderate growth, but at about half the rate as in DRY270. As a result, the difference between DRY270 and DRY144 becomes noticeable just after day 3 and increases through day 4 , remaining steady thereafter up to day 6. In DRY90, the intensity also follows DRY270 up to about day 3. It then undergoes a 10-12-h period of weakening followed by slow strengthening through 4.4 days, rapid intensification through day 5 , and then moderate intensification thereafter. Finally, DRY0 undergoes an approximately daylong delay in initial development, clearly tied to the general suppression of convection during the period of axisymmetrization of the dry air initially in the vortex core (see Fig. 7i). This delay is followed by a period of moderate intensification through about 3.5 days and then a period of no intensification through 4.5 days, after which moderate intensification resumes. Clearly, there are events that occur in the 2-4-day time frame that slow or prevent intensification in DRY144, DRY90, and DRY0. To further explain intensity differences, we next examine a characteristic of the convective evolution that is common to the three simulations and enhanced with increasing dry air.

In general, the intensification of a vortex will be larger when the azimuthal mean diabatic heating occurs at a smaller radius closer to the high-vorticity core, whereas heating at larger radii away from the core will contribute much less to intensification (Hack and Schubert 1986; Montgomery and Enagonio 1998; Möller and Montgomery 2000; Nolan et al. 2007a; Bui et al. 2009). In this regard, Fig. 11 shows the evolution of the radial distribution of azimuthally averaged diabatic heating at the 3-km level. As in Fig. 10, we use the DRY270 case as our reference for comparison because it has the same intensity as CNTL and includes the dry air. In DRY270 (Fig. 11a), the heating in the nascent eyewall increases gradually through the first 


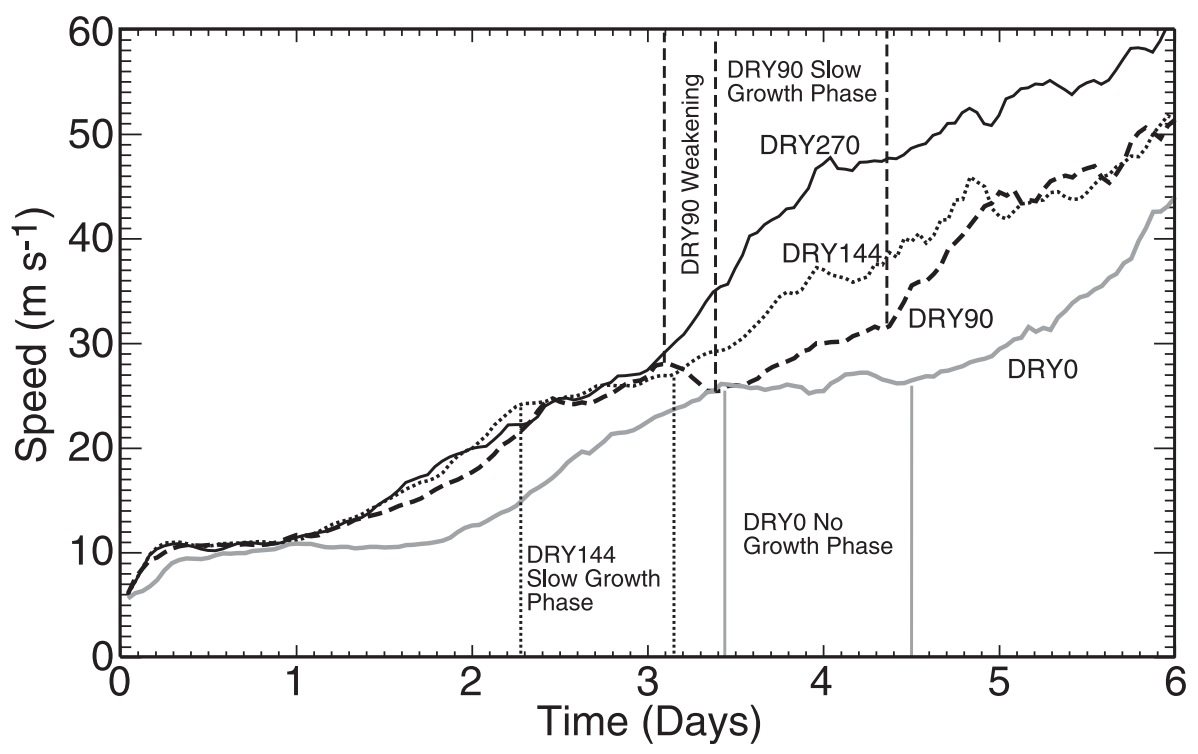

FIG. 10. Time series of maximum azimuthally averaged tangential wind speed for all simulations with an initial west-to-east-oriented dry air boundary for the first 6 days of simulation. Vertical lines indicate the start and end times for particular periods of slower growth compared to DRY270, with the line style matching the corresponding wind speed curve for the different experiments.

3 days while contracting to smaller radius. This contraction does not occur steadily, as in CNTL (not shown), but occurs with two brief periods of no contraction around 2-2.5 days and 3 days. The heating increases markedly with the onset of rapid intensification after 3 days. A dashed line is used to indicate the axis of peak heating and is overlaid in the plots from other simulations to facilitate comparisons. Figure $11 \mathrm{~b}$ shows the pattern of diabatic heating for the DRY144 simulation, which is generally similar to DRY270 barring a couple of exceptions. First, prior to 2.3 days, the maximum heating contracts to smaller radius and is larger than in DRY270, consistent with the slightly greater maximum wind speed at that time. Just after 2.3 days, the heating peak stops contracting, the heating becomes smaller, and the rate of intensification slows. Second, a brief lull and radially outward displacement occurs near 3 days, followed by a more gradual increase in heating in the eyewall during the subsequent period of moderate intensification. The lull in and outward displacement of the heating exactly coincides with the separation of the tangential velocity curves in Fig. 10 at 3 days between DRY270 and DRY144. In the DRY90 simulation (Fig. 11c), the weakening phase coincides with a sharp outward displacement of the heating (indicated by the dotted curve) just after day 3 , while the slow growth phase corresponds to a slow recovery of the radius of peak heating toward the DRY270 case. Finally, in the DRY0 case (Fig. 11d), the first period of no growth within the first 2 days corresponds to a general absence of significant heating as the dry air suppresses convection, while the second period of no growth beginning near 3.5 days coincides with a large outward displacement of the heating relative to DRY270 between 3 and 4.5 days. Intensification resumes (see Fig. 10) once the heating shifts back toward smaller radius (near $30 \mathrm{~km}$ ) at 4.5 days.

The outward displacement of diabatic heating in DRY144, DRY90, and DRY0 relative to DRY270 is related to the formation and outward movement of a highly asymmetric spiraling rainband that forms in each simulation. The asymmetry in precipitation increases when dry air begins nearer to the center of the vortex (e.g., section 4) and the subsequent rainbands encounter increasingly drier environments. For example, moving from DRY270 to DRY144, DRY90, and DRY0 (Figs. $12 \mathrm{a}-\mathrm{d})$, just radially outward from the rainband on the southwestern side of the storm at 3 days, $\theta_{e}$ is near 340 , 338 , and $336 \mathrm{~K}$, and then less than $336 \mathrm{~K}$, respectively. As will be shown below, the interaction with their environment affects the duration and outward movement of the rainbands as well as the resulting cold-pool $\theta_{e}$ decrease within the primary boundary layer inflow region.

Figures 13-16 use 6-h averaged ${ }^{2}$ near-surface $\theta_{e}$ and rain mixing ratio for the DRY270, DRY144, DRY90, and DRY0 simulations to demonstrate the evolution of

\footnotetext{
${ }^{2}$ The fields have been smoothed to improve legibility of the figures. We use the Interactive Data Language's (IDL) twodimensional "median" filter of 7-point width. Median smoothing replaces each point with the median (the value with an equal number of values above and below it) of the two-dimensional neighborhood of a given width.
} 
a) DRY270
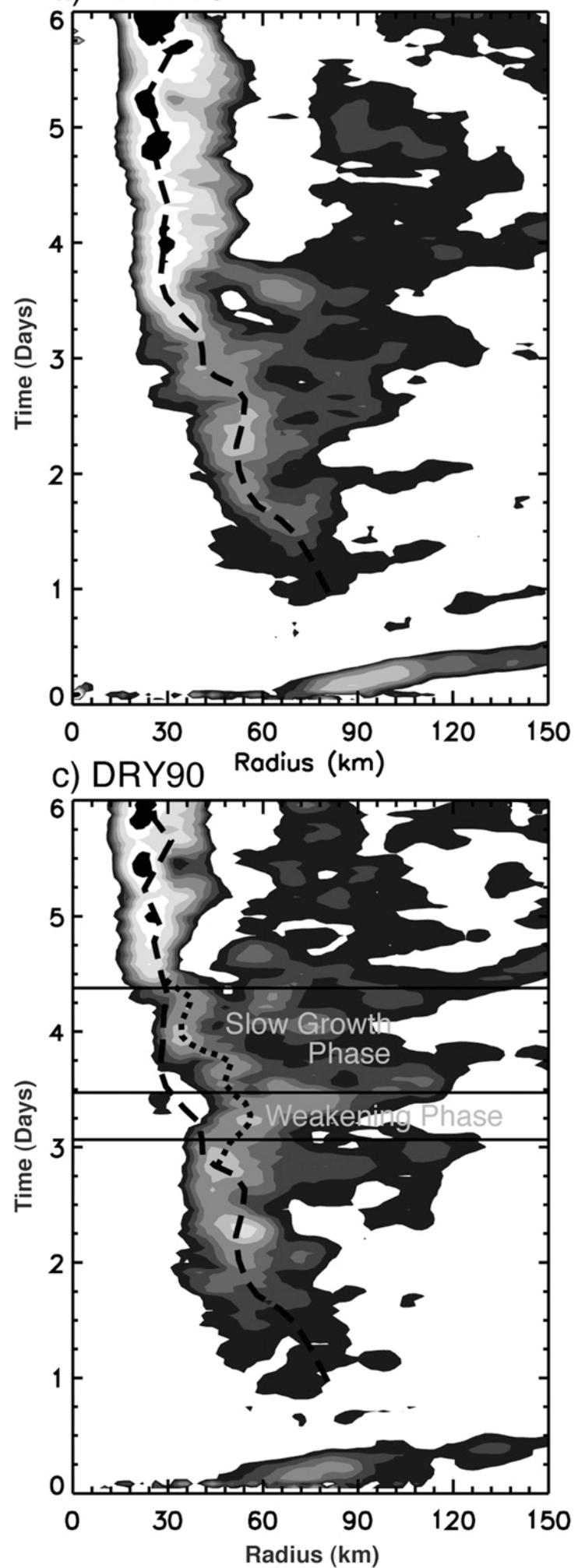

b) DRY144

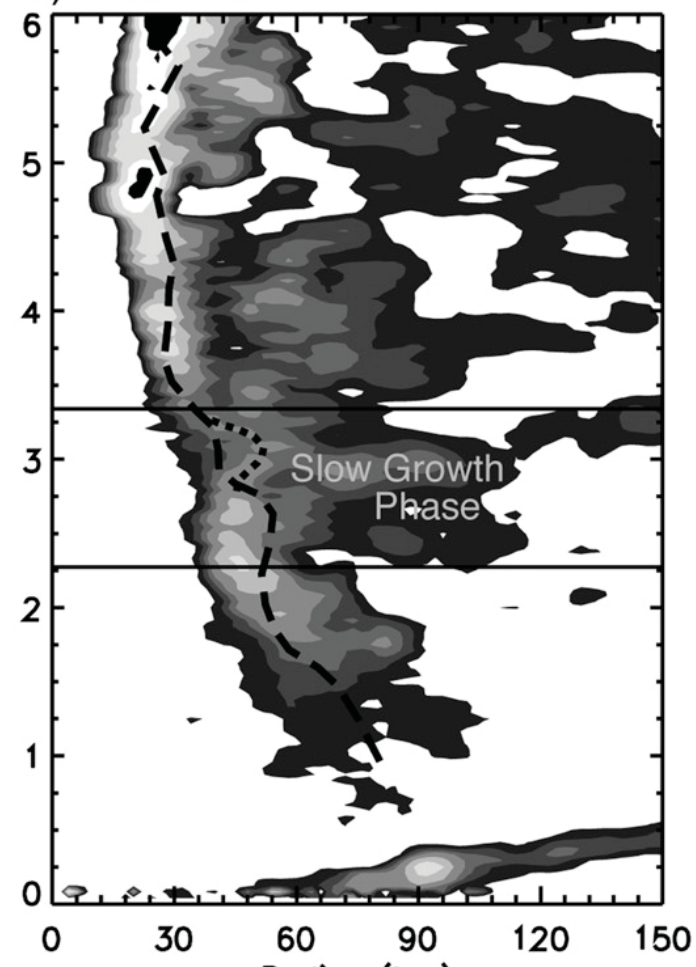

d) DRY0 Rodius $(\mathrm{km})$

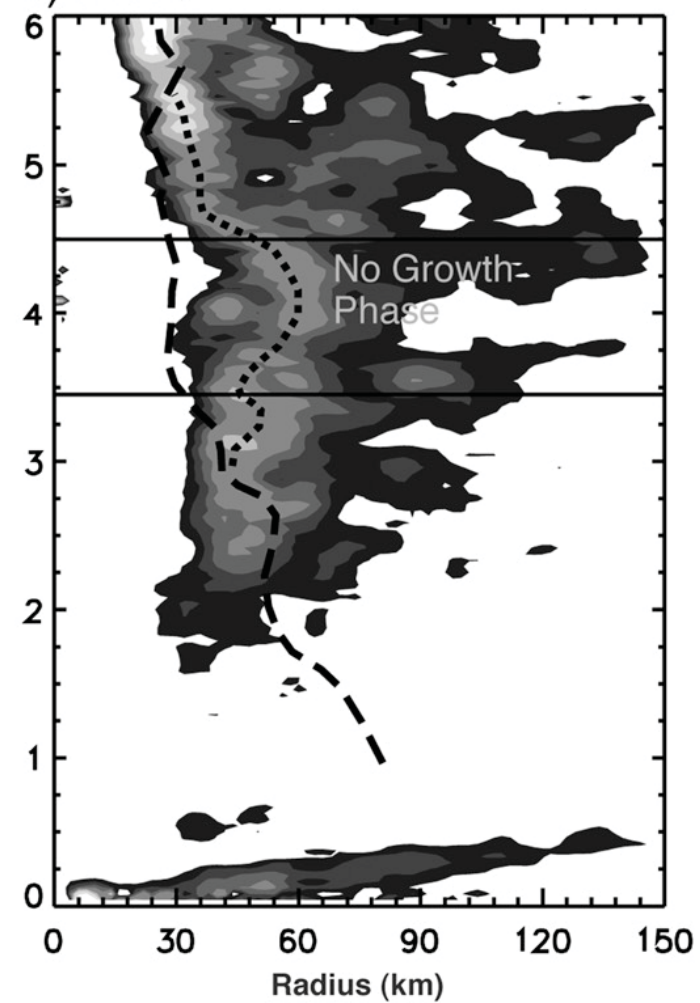

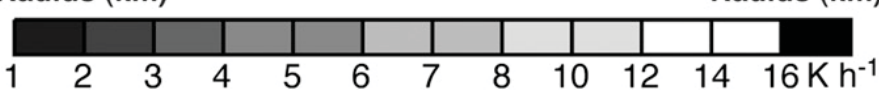

FIG. 11. Radius vs time distributions of the azimuthally averaged diabatic heating (shading) at $3 \mathrm{~km}$ for (a) DRY270, (b) DRY144, (c) DRY90, and (d) DRY0. The dashed line indicates the axis of peak heating in the DRY270 simulation. The dotted lines in (b)-(d) show the axis of peak heating in the other simulations where it lies at larger radius relative to the DRY270 case. The periods of slower growth (from Fig. 10) are indicated by the horizontal lines. 

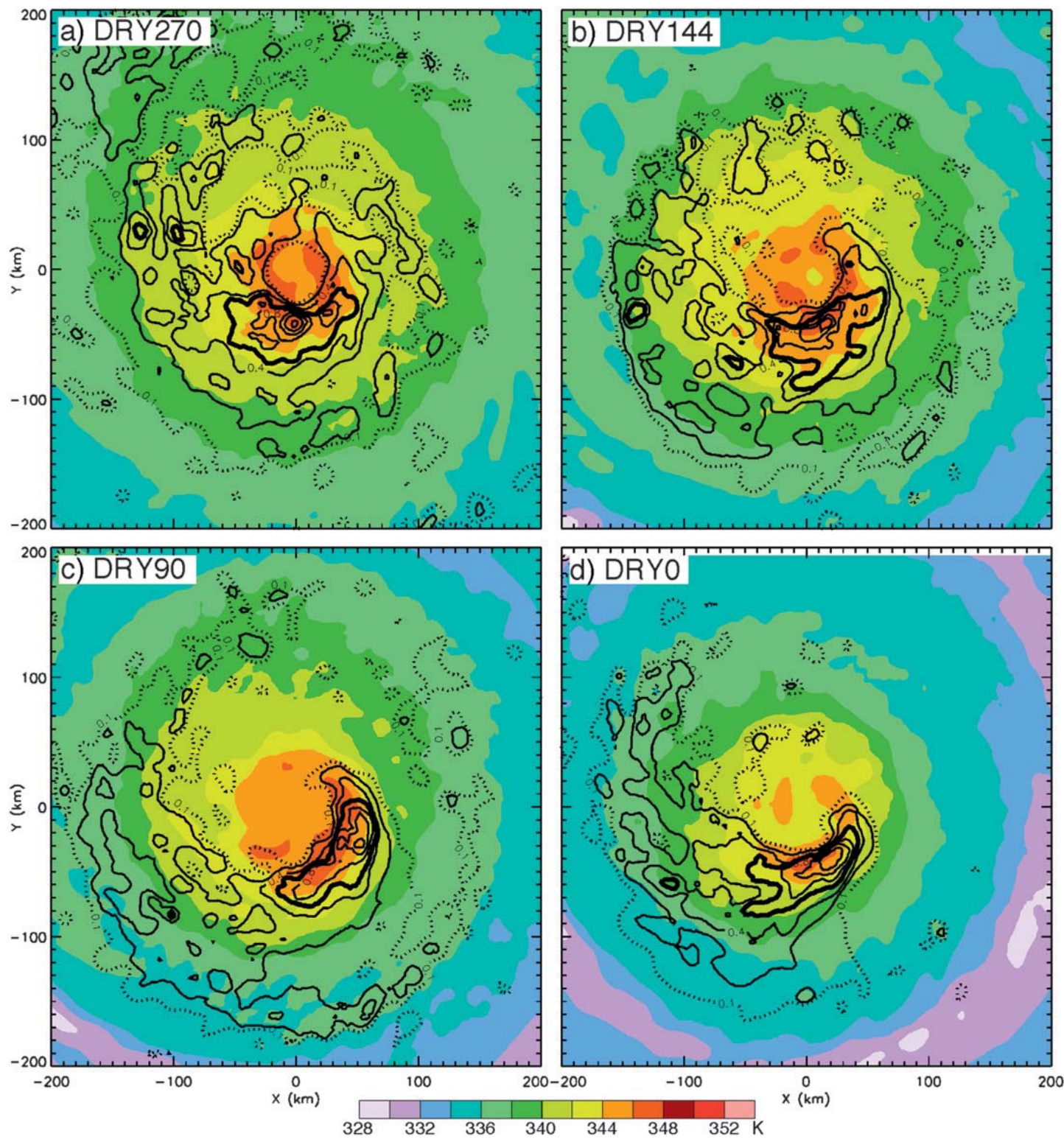

FIG. 12. Six-hour averaged $\theta_{e}$ (shading) at $3 \mathrm{~km}$ for the period 3-3.25 days from the 2-km grid for the (a) DRY270, (b) DRY144, (c) DRY90, and (d) DRY0 runs. Contours show rain mixing ratios at $0.2 \mathrm{~g} \mathrm{~kg}^{-1}$ interval (solid lines) plus an additional contour at $0.1 \mathrm{~g} \mathrm{~kg}^{-1}$ (dotted lines). The contour at $0.6 \mathrm{~g} \mathrm{~kg}^{-1}$ is highlighted by the thick contour.

the rainbands that impact storm intensification in the 2-4-day time frame. Dark red lines indicate the axes of peak inflow near the surface. In DRY270, at 2.5-2.75 days (Fig. 13a), the lowest $\theta_{e}$ air extends from the northern side around to the western and southern sides of the storm. Rain extends around the nascent eyewall, although it is weaker on the northeastern side. Over the next 12-36 h, the rain becomes increasingly asymmetric, with maximum values on the southern side and with the widest radial extent occurring between 3.5 and 4 days (Figs. 13c,d). During the same time, there is a gradual increase in $\theta_{e}$ values, particularly within about $100 \mathrm{~km}$ from the center. The degree of asymmetry in structure does not prevent rapid intensification during this time period since diabatic heating remains concentrated in the eyewall.

In DRY144, a prominent asymmetry in rainfall structure is apparent at 2.5 days, with intense rainfall in the southern eyewall and little precipitation in the northern eyewall (Fig. 14a). At 3 days (Fig. 14b), precipitation increases on the southwestern side outside of the eyewall, cooling the boundary layer along the main inflow region (red line). This time corresponds to the brief period of diminished and outwardly displaced average latent heating relative to DRY270 (Fig. 11b). Over the next $24 \mathrm{~h}$ (Figs. 14c,d), as the rate of intensification increases, the rainfall in the eyewall intensifies and 

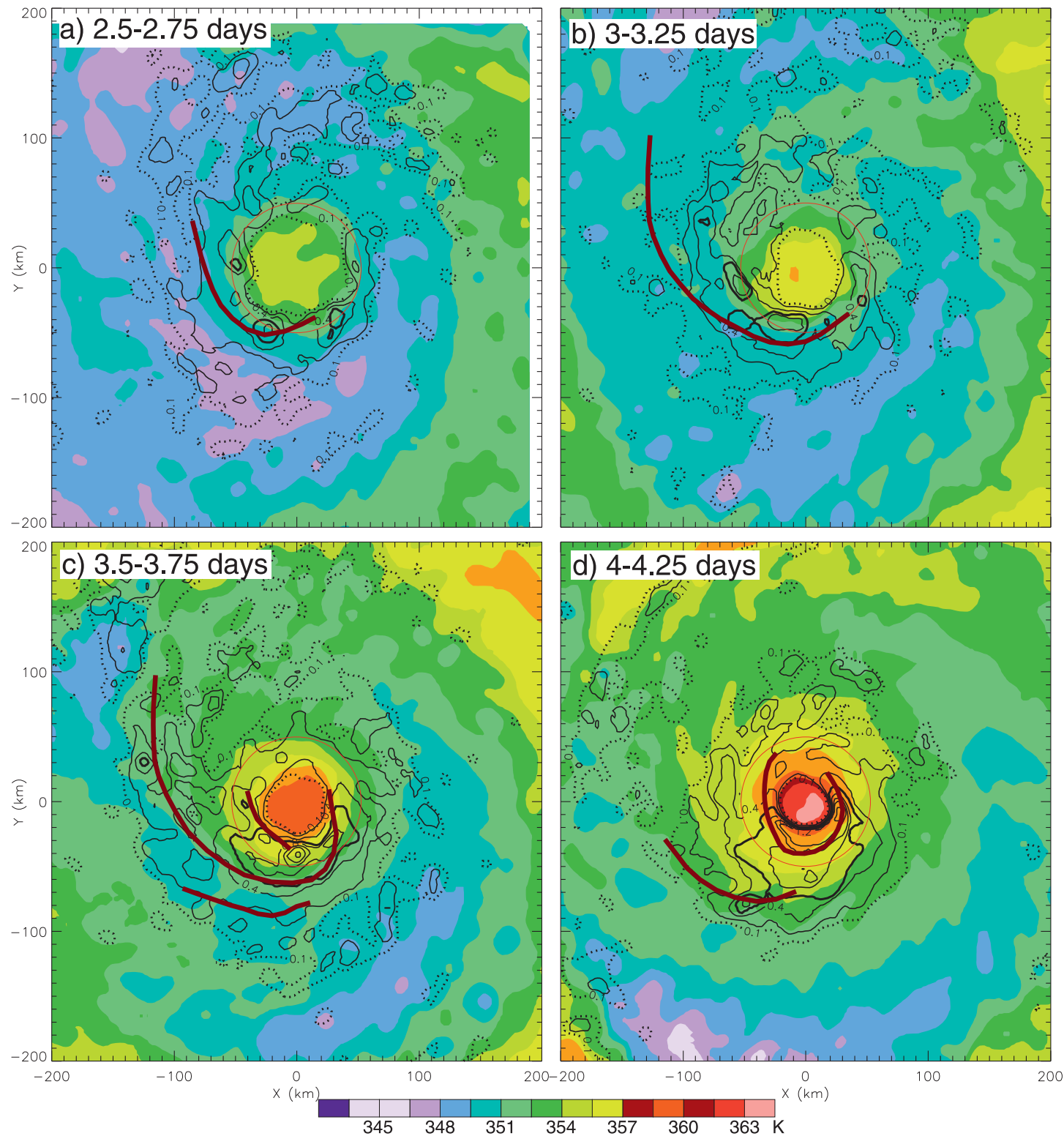

FIG. 13. Six-hour averaged $\theta_{e}$ (shading) at the lowest model level $(90 \mathrm{~m})$ at the specified times from the 2-km grid for the DRY270 run. Contours show rain mixing ratios at $0.2 \mathrm{~g} \mathrm{~kg}^{-1}$ interval (solid lines) plus an additional contour at $0.1 \mathrm{~g} \mathrm{~kg}^{-1}$ (dotted lines). The contour at $0.6 \mathrm{~g} \mathrm{~kg}^{-1}$ is highlighted by the thick contour. The red circle (of fixed size) is used as a reference to highlight changes in precipitation radius with time. Dark red lines are drawn along the axes of maximum radial velocities.

contracts to smaller radius while $\theta_{e}$ values along and upstream of the peak inflow increase by $\sim 3 \mathrm{~K}$.

The rainband development is even more dramatic in DRY90 from 3 to 3.5 days (Figs. 15b,c), where the highly asymmetric rainband spirals outward from the southeastern eyewall around to the west. The rainband persists for $\sim 24-30 \mathrm{~h}$, maintaining cooler $\theta_{e}$ values in the inflow layer and either weakening or significantly slowing intensification during this period. By $\sim 4.25$ days (Fig. 15d), the spiraling rainband and cooler air has moved far out from the center while rain has reintensified at smaller radius in the eyewall and $\theta_{e}$ values have quickly increased behind the rainband.

Finally, in DRY0, the very pronounced rainfall asymmetry evident at 2.75 days (Fig. 16a) gradually expands outward to larger radius on the southwestern side of the storm over the next 30-36 h (Figs. 16b-d), cooling the boundary layer inflow and substantially reducing the rain in the eyewall region. By 4.5-5 days and beyond (Figs. 16d-f), boundary layer $\theta_{e}$ values in the inner-core region behind the rainband increase quickly, intense rainfall redevelops in the eyewall, and the radius of the 

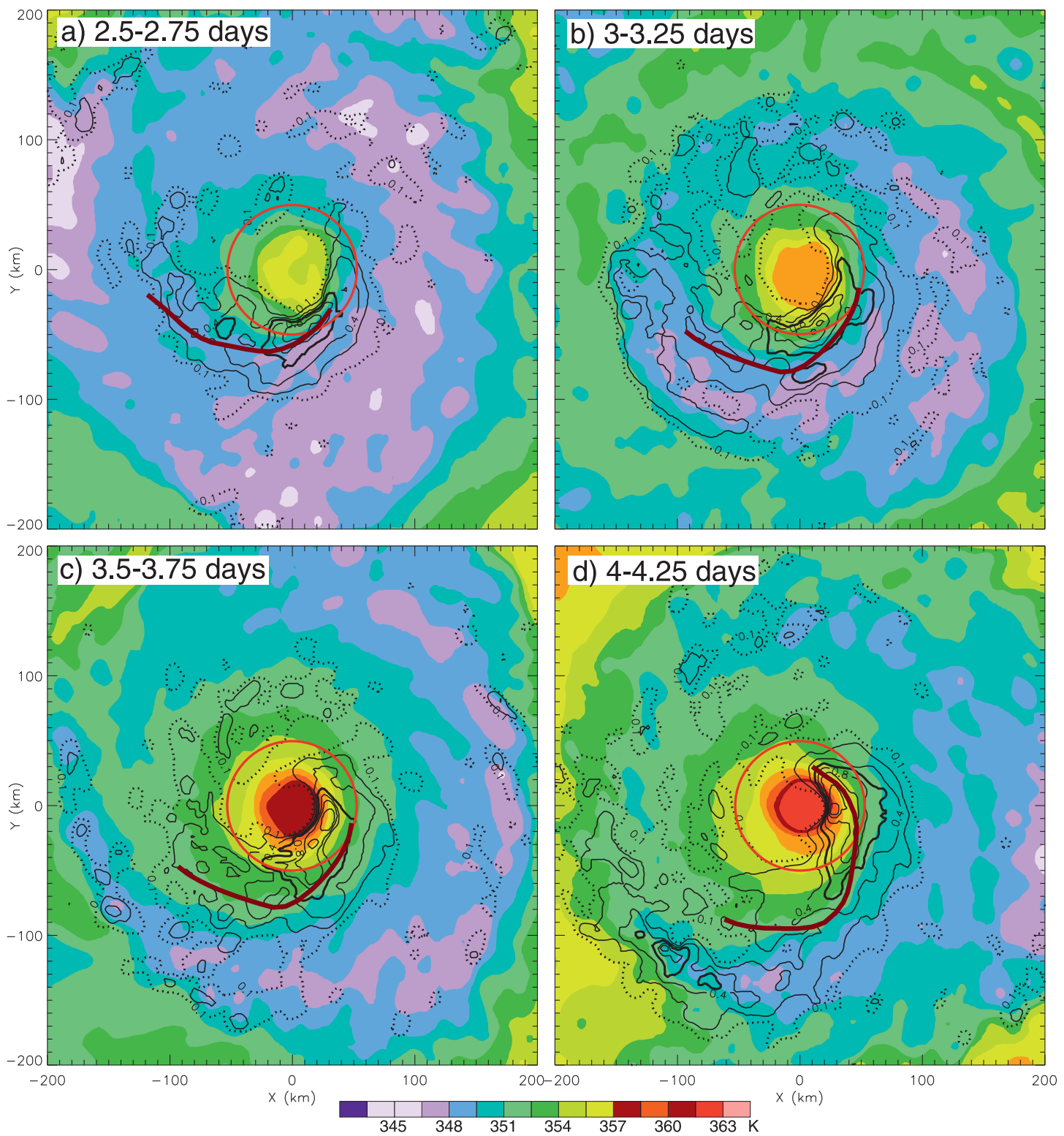

FIG. 14. As in Fig. 13, but for the DRY144 simulation.

eyewall contracts. Similar to other simulations, the expansion of the outward spiraling rainband coincides with the period of no growth.

In summary, as asymmetric dry air is initialized closer to the vortex core, it increasingly suppresses convection, inducing an increasingly prominent wavenumber-1 asymmetry in storm structure. After axisymmetrization, midlevel $\theta_{e}$ just outside of the moist core of the storm is lower when dry air is initially closer to the vortex center. With lower ambient $\theta_{e}$ values, the spiral rainband development becomes more pronounced and persistent, the $\theta_{e}$ in the area of strongest inflow becomes lower, there is a larger departure of latent heating from the vortex core, and there is a greater reduction in the intensification rate. While the relationships among rainband development, latent heating structure changes, and intensification rates have been demonstrated, the exact means by which the dry air makes the rainbands more pronounced and prolonged and the extent of the role of boundary layer cooling remain unclear.

\section{Conclusions}

This study has focused on the impact of dry midlevel air on the development of tropical cyclones, specifically addressing the role of the dry air in enhancing cold downdraft activity and suppressing storm development. The WRF model is used to construct two sets of idealized 


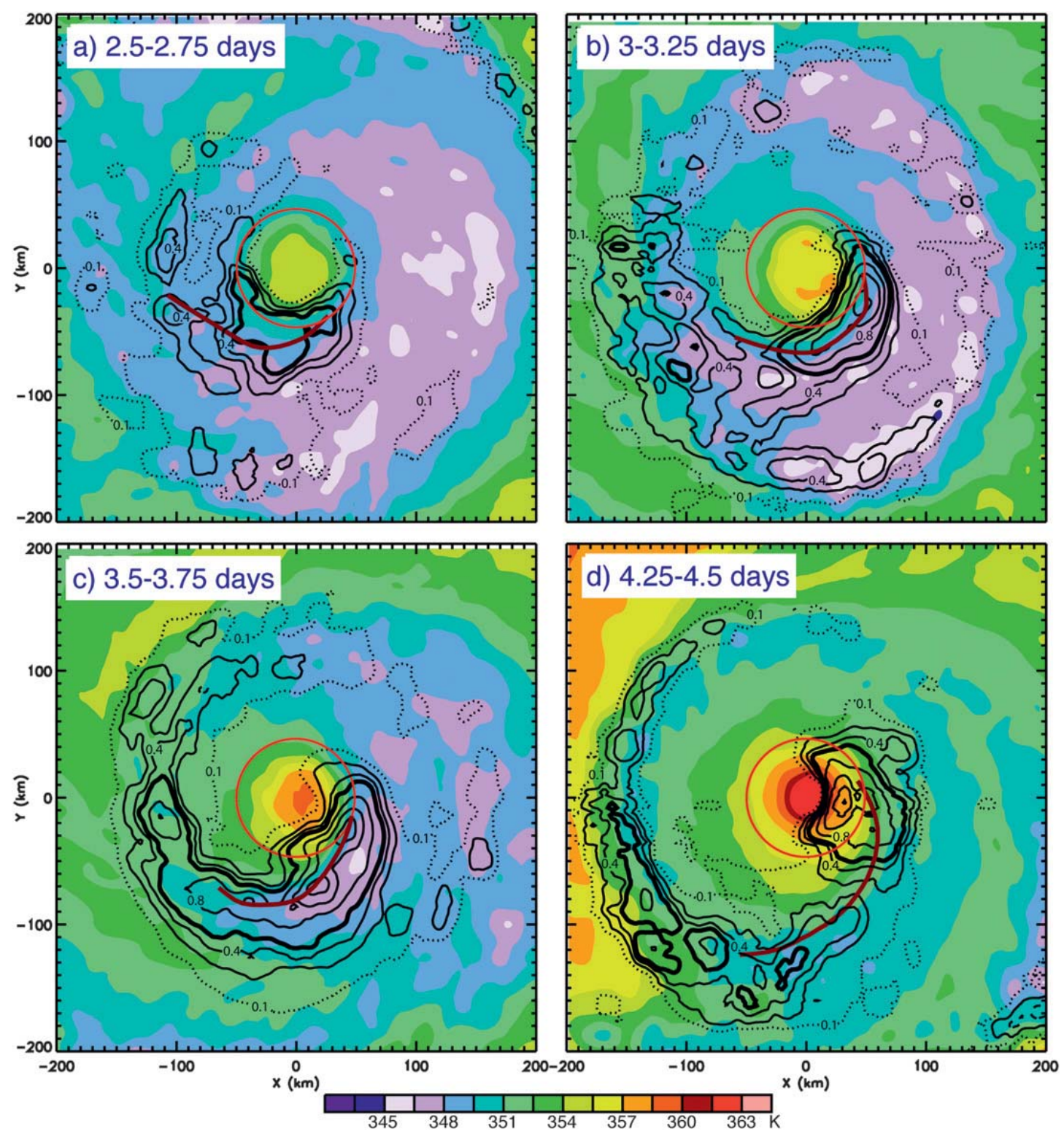

FIG. 15. As in Fig. 13, but for the DRY90 simulation.

simulations of hurricane development with a non-SAL sounding: 1 ) a set of simulations with dry air located north of the vortex center by distances ranging from 0 to $270 \mathrm{~km}$ and 2) a second set of simulations with dry air completely surrounding the vortex, but with moist envelopes in the vortex core ranging in size from 0 to $150 \mathrm{~km}$ in radius.

For the first set of simulations, no impact of the dry air was seen for dry layers located more than $270 \mathrm{~km}$ north of the vortex center $(\sim 3$ times the initial radius of maximum wind). As the dry air boundary was moved closer to the vortex center, the tangential flow of the vortex increasingly wrapped the dry air into the region of inner-core convection. The dry air suppressed initial convective development, leading to asymmetry of the convective vertical mass flux and slower storm development. Note that all simulations eventually reached the same steady-state intensity.

For the second set of simulations, the presence of dry air throughout the domain, including the vortex center, substantially suppressed storm development, delaying intensification at least 3 days. However, dry air throughout the vortex is rather unrealistic. Observations suggest that most systems have a pocket or envelope of high humidity within the vortex core. When moist envelopes (consisting of the non-SAL thermodynamic characteristics) were included within the vortex even out to a radius less than the initial radius of maximum wind, 

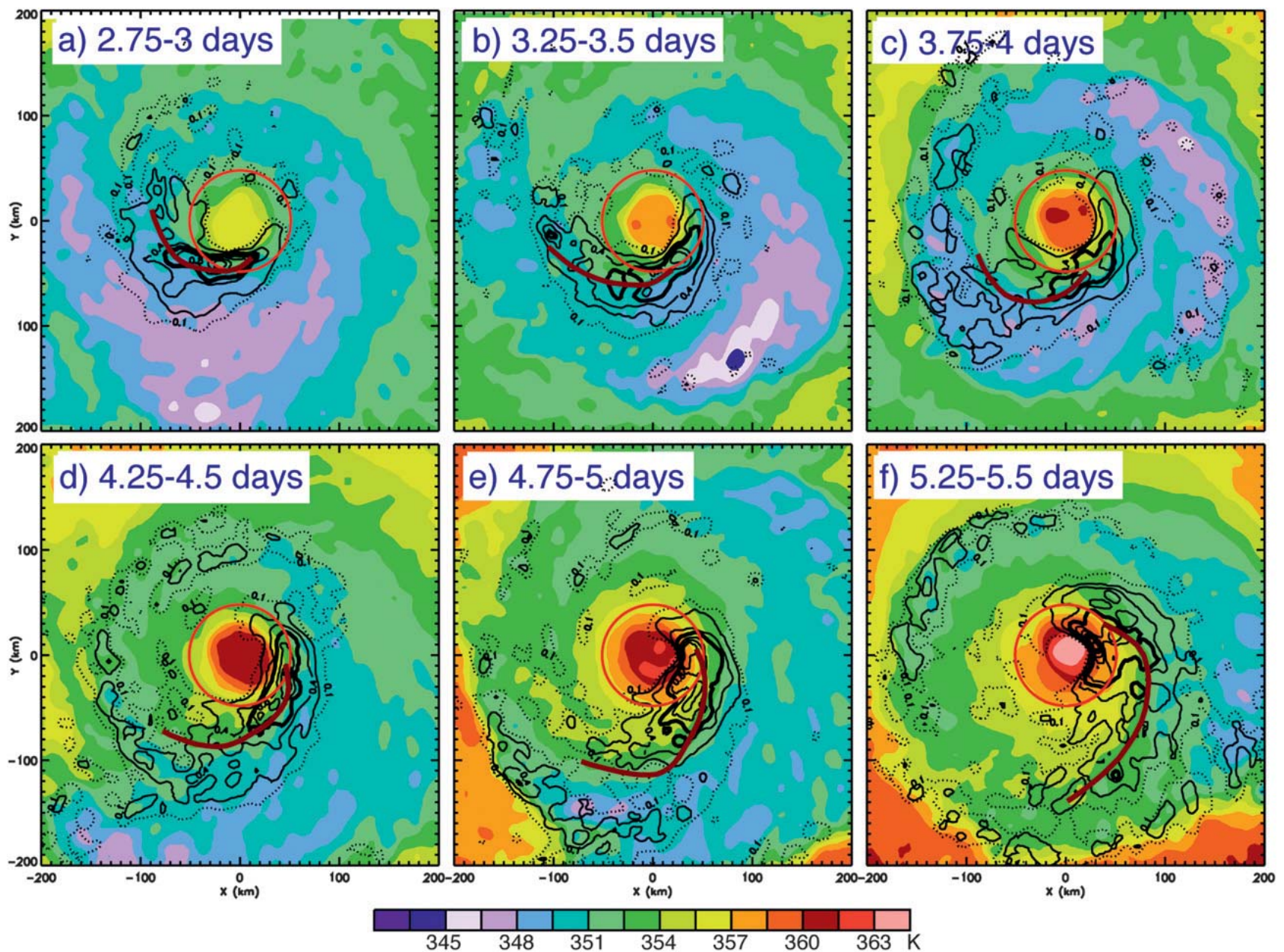

FIG. 16. As in Fig. 13, but for the DRY0 simulation.

the storm intensity evolved in a manner very similar to the control run without dry air, but the storm size was significantly reduced, consistent with the findings of Hill and Lackmann (2009).

Downdraft cooling of the PBL during the initial ingestion of dry air (the first 1-3 days) appears to have had little impact on storm intensification except in the DRY0 simulation, where a clear suppression of development is seen during the first 2 days. After that time, differences in the rate of intensification are shown to be related to the development of an outwardly spiraling asymmetric rainband that increasingly slows storm growth as dry air is started closer to the storm center. Interestingly, DRYALL75 produces the most downdraft cooling and yet intensifies at a rate similar to CNTL, likely because the dry air maintains a symmetric zone of convection in the eyewall that locks the diabatic heating onto the region of higher vorticity in the storm core. This result suggests that strong downdraft cooling in and of itself does not necessarily inhibit intensification. Instead, it may need to be coupled with the production of storm asymmetries that have the potential to dramatically change the radial distribution of diabatic heating and push the heating peak away from the high vorticity core.

The results above suggest that proximity of dry air near or even surrounding a moist vortex should not be interpreted as an indication of likely suppression of tropical storm development or a mechanism for storm weakening (e.g., Shu and Wu 2009). The dry air must approach very close to the inner core of the storm, to a distance comparable to or just outside of the radius of maximum winds, in order to slow the intensification of a developing tropical cyclone. Otherwise, the dry air apparently acts only to affect the size of the storm (Kimball 2006; Hill and Lackmann 2009). The results also suggest that the dry air must act in tandem with other processes such as vertical wind shear to produce more substantial inhibiting effects (e.g., Shelton and Molinari 2009).

The simulations in this study involve highly idealized environments with no mean flow in the environment of the vortex. It is very possible that the impact of dry air 
might be enhanced when combined with more complex environments, including steering flow and vertical wind shear. The idealized simulations obviously only represent storms forming in conditions with little or no wind shear, but such conditions are not uncommon for storms that become major hurricanes. A future study will address the added complexity of mean flow and sheared environments.

Acknowledgments. This work was supported by Dr. Ramesh Kakar at NASA Headquarters with funds from the NASA Hurricane Science Research Program. J. A. Sippel contributed to this study while under the NASA Postdoctoral Program and while working for the Goddard Earth Sciences and Technology Center. D. S. Nolan was supported by NSF Grant ATM-0851021. The simulations were conducted on NASA Center for Computational Sciences facilities. We wish to thank the three anonymous reviewers for their very helpful comments that greatly helped to improve the manuscript.

\section{REFERENCES}

Braun, S. A., 2002: A cloud-resolving simulation of Hurricane Bob (1991): Storm structure and eyewall buoyancy. Mon. Wea. Rev., 130, 1573-1592.

- 2006: High-resolution simulation of Hurricane Bonnie (1998). Part II: Water budget. J. Atmos. Sci., 63, 43-64.

_ 2010: Reevaluating the role of the Saharan Air Layer in Atlantic tropical cyclogenesis and evolution. Mon. Wea. Rev., 138, 2007-2037.

—, M. T. Montgomery, K. J. Mallen, and P. D. Reasor, 2010: Simulation and interpretation of the genesis of Tropical Storm Gert (2005) as part of the NASA Tropical Cloud Systems and Processes Experiment. J. Atmos. Sci., 67, 9991025.

Bui, H. H., R. K. Smith, M. T. Montgomery, and J. Peng, 2009: Balanced and unbalanced aspects of tropical cyclone intensification. Quart. J. Roy. Meteor. Soc., 135, 1715-1731.

Davis, C. A., and Coauthors, 2008a: Prediction of landfalling hurricanes with the Advanced Hurricane WRF model. Mon. Wea. Rev., 136, 1990-2005.

— S. C. Jones, and M. Riemer, 2008b: Hurricane vortex dynamics during Atlantic extratropical transition. J. Atmos. Sci., 65, 714-736.

DeMaria, J. A. Knaff, and B. H. Connell, 2001: A tropical cyclone genesis parameter for the tropical Atlantic. Wea. Forecasting, 16, 219-233.

Dunion, J. P., and C. S. Velden, 2004: The impact of the Saharan air layer on Atlantic tropical cyclone activity. Bull. Amer. Meteor. Soc., 85, 353-365.

— , and C. S. Marron, 2008: A reexamination of the Jordan mean tropical sounding based on awareness of the Saharan Air Layer: Results from 2002. J. Climate, 21, 5242-5253.

Dunkerton, T. J., M. T. Montgomery, and Z. Wang, 2009: Tropical cyclogenesis in a tropical wave critical layer: Easterly waves. Atmos. Chem. Phys., 9, 5587-5646.

Emanuel, K. A., 1989: The finite-amplitude nature of tropical cyclogenesis. J. Atmos. Sci., 46, 3431-3456.
Gray, W. M., 1975: Tropical cyclone genesis. Colorado State University, Department of Atmospheric Science Paper 234, 121 pp. , 1979: Hurricanes: Their formation, structure and likely role in the tropical circulation. Meteorology over Tropical Oceans, D. B. Shaw, Ed., Royal Meteorological Society, 155-218.

_ 1998: The formation of tropical cyclones. Meteor. Atmos. Phys., 67, 37-69.

Hack, J. J., and W. H. Schubert, 1986: Nonlinear response of atmospheric vortices to heating by organized cumulus convection. J. Atmos. Sci., 43, 1559-1573.

Hill, K. A., and G. M. Lackmann, 2009: Influence of environmental humidity on tropical cyclone size. Mon. Wea. Rev., 137, 32943315.

Hong, S.-Y., J. Dudhia, and S.-H. Chen, 2004: A revised approach to ice microphysical processes for the bulk parameterization of clouds and precipitation. Mon. Wea. Rev., 132, 103-120.

—, Y. Noh, and J. Dudhia, 2006: A new vertical diffusion package with an explicit treatment of entrainment processes. Mon. Wea. Rev., 134, 2318-2341.

Hopsch, S. B., C. D. Thorncroft, and K. R. Tyle, 2010: Analysis of African easterly wave structures and their role in influencing tropical cyclogenesis. Mon. Wea. Rev., 138, 1399-1419.

Jones, T. A., D. J. Cecil, and J. Dunion, 2007: The environmental and inner-core conditions governing the intensity of Hurricane Erin (2001). Wea. Forecasting, 22, 708-725.

Kain, J. S., and J. M. Fritsch, 1990: A one-dimensional entraining/ detraining plume model and its application in convective parameterization. J. Atmos. Sci., 47, 2784-2802.

— models: The Kain-Fritcsh scheme. The Representation of Cumulus Convection in Numerical Models, Meteor. Monogr., No. 46, Amer. Meteor. Soc., 165-170.

Kaplan, J., and M. DeMaria, 2003: Large-scale characteristics of rapidly intensifying tropical cyclones in the North Atlantic basin. Wea. Forecasting, 18, 1093-1108.

Kimball, S. K., 2006: A modeling study of hurricane landfall in a dry environment. Mon. Wea. Rev., 134, 1901-1918.

Liu, Y., D.-L. Zhang, and M. K. Yau, 1997: A multi-scale numerical study of Hurricane Andrew (1992). Part I: Explicit simulations and verification. Mon. Wea. Rev., 125, 3073-3093.

McBride, J. L., 1981: Observational analysis of tropical cyclone formation. Part I: Basic description of data sets. J. Atmos. Sci., 38, 1117-1131.

_ , and R. Zehr, 1981: Observational analysis of tropical cyclone formation. Part II: Comparison of non-developing versus developing systems. J. Atmos. Sci., 38, 1132-1151.

Möller, J. D., and M. T. Montgomery, 2000: Tropical cyclone evolution via potential vorticity anomalies in a three-dimensional balance model. J. Atmos. Sci., 57, 3366-3387.

Montgomery, M. T., and J. Enagonio, 1998: Tropical cyclogenesis via convectively forced vortex Rossby waves in a threedimensional quasigeostrophic model. J. Atmos. Sci., 55, 31763207.

Noh, Y., W. G. Cheon, S. Y. Hong, and S. Raasch, 2003: Improvement of the K-profile model for the planetary boundary layer based on large eddy simulation data. Bound.-Layer Meteor., 107, 401-427.

Nolan, D. S., 2007: What is the trigger for tropical cyclogenesis? Aust. Meteor. Mag., 56, 241-266.

— clogenesis to wind shear in higher SST environments. Geophys. Res. Lett., 35, L14805, doi:10.1029/2008GL034147. 
, Y. Moon, and D. P. Stern, 2007a: Tropical cyclone in tensification from asymmetric convection: Energetics and efficiency. J. Atmos. Sci., 64, 3377-3405.

_, E. D. Rappin, and K. A. Emanuel, 2007b: Tropical cyclogenesis sensitivity to environmental parameters in radiative-convective equilibrium. Quart. J. Roy. Meteor. Soc., 133, 2085-2107.

_ J. A. Zhang, and D. P. Stern, 2009: Evaluation of planetary boundary layer parameterizations in tropical cyclones by comparison of in situ observations and high-resolution simulations of Hurricane Isabel (2003): Part I: Initialization, maximum winds, and the outer-core boundary layer. Mon. Wea. Rev., 137, 3651-3674.

Powell, M. D., 1990: Boundary layer structure and dynamics in outer hurricane rainbands. Part II: Downdraft modification and mixed-layer recovery. Mon. Wea. Rev., 118, 918-938.

Shelton, K. L., and J. Molinari, 2009: Life of a six-hour hurricane. Mon. Wea. Rev., 137, 51-67.

Shu, S., and L. Wu, 2009: Analysis of the influence of the Saharan air layer on tropical cyclone intensity using AIRS/Aqua data. Geophys. Res. Lett., 36, L09809, doi:10.1029/2009GL037634.

Sippel, J. A., S. A. Braun, and C.-L. Shie, 2011: An ensemble analysis of environmental influences on the strength of Tropical Storm Debby (2006). J. Atmos. Sci., 68, 2557-2581.

Skamarock, W. C., J. B. Klemp, J. Dudhia, D. O. Gill, D. M. Barker, W. Wang, and J. G. Powers, 2005: A description of the Advanced Research WRF version 2. NCAR Tech. Note NCAR/TN-468+STR, 88 pp.
Smith, R. K., M. T. Montgomery, and N. Van Sang, 2009: Tropicalcyclone spin-up revisited. Quart. J. Roy. Meteor. Soc., 135, 1321-1335.

Sun, D., K. M. Lau, and M. Kafatos, 2008: Contrasting the 2007 and 2005 hurricane seasons: Evidence of possible impacts of Saharan dry air and dust on tropical cyclone activity in the Atlantic basin. Geophys. Res. Lett., 35, L15405, doi:10.1029/ 2008GL034529.

,,--- Z. Boybeyi, G. Leptoukh, C. Yang, and R. Yang, 2009: Numerical simulations of the impacts of the Saharan air layer on Atlantic tropical cyclone development. J. Climate, 22, $6230-6250$

Vizy, E. K., and K. H. Cook, 2009: Tropical storm development from African easterly waves in the eastern Atlantic: A comparison of two successive waves using a regional model as part of NASA AMMA 2006. J. Atmos. Sci., 66, 3313-3334.

Wang, Z., M. T. Montgomery, and T. J. Dunkerton, 2010: Genesis of pre-Hurricane Felix (2007). Part I: The role of the easterly wave critical layer. J. Atmos. Sci., 67, 1711-1729.

Wu, L., 2007: Impact of Saharan air layer on hurricane peak intensity. Geophys. Res. Lett., 34, L09802, doi:10.1029/2007GL029564.

— S. A. Braun, J. J. Qu, and X. Hao, 2006: Simulating the formation of Hurricane Isabel (2003) with AIRS data. Geophys. Res. Lett., 33, L04804, doi:10.1029/2005GL024665.

Zhang, D.-L., and R. A. Anthes, 1982: A high-resolution model of the planetary boundary layer-Sensitivity tests and comparisons with SESAME-79 data. J. Appl. Meteor., 21, 1594-1609. 